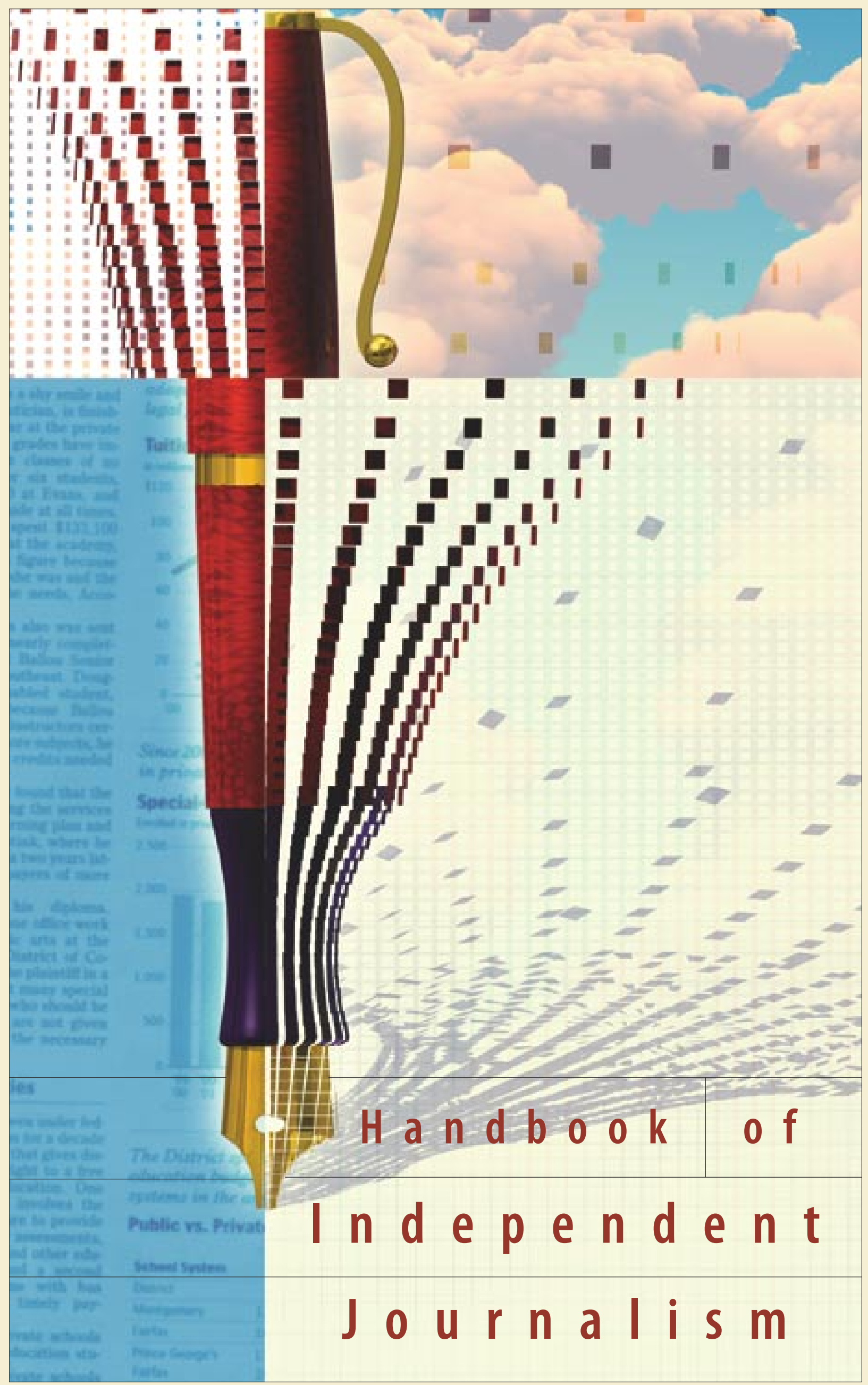




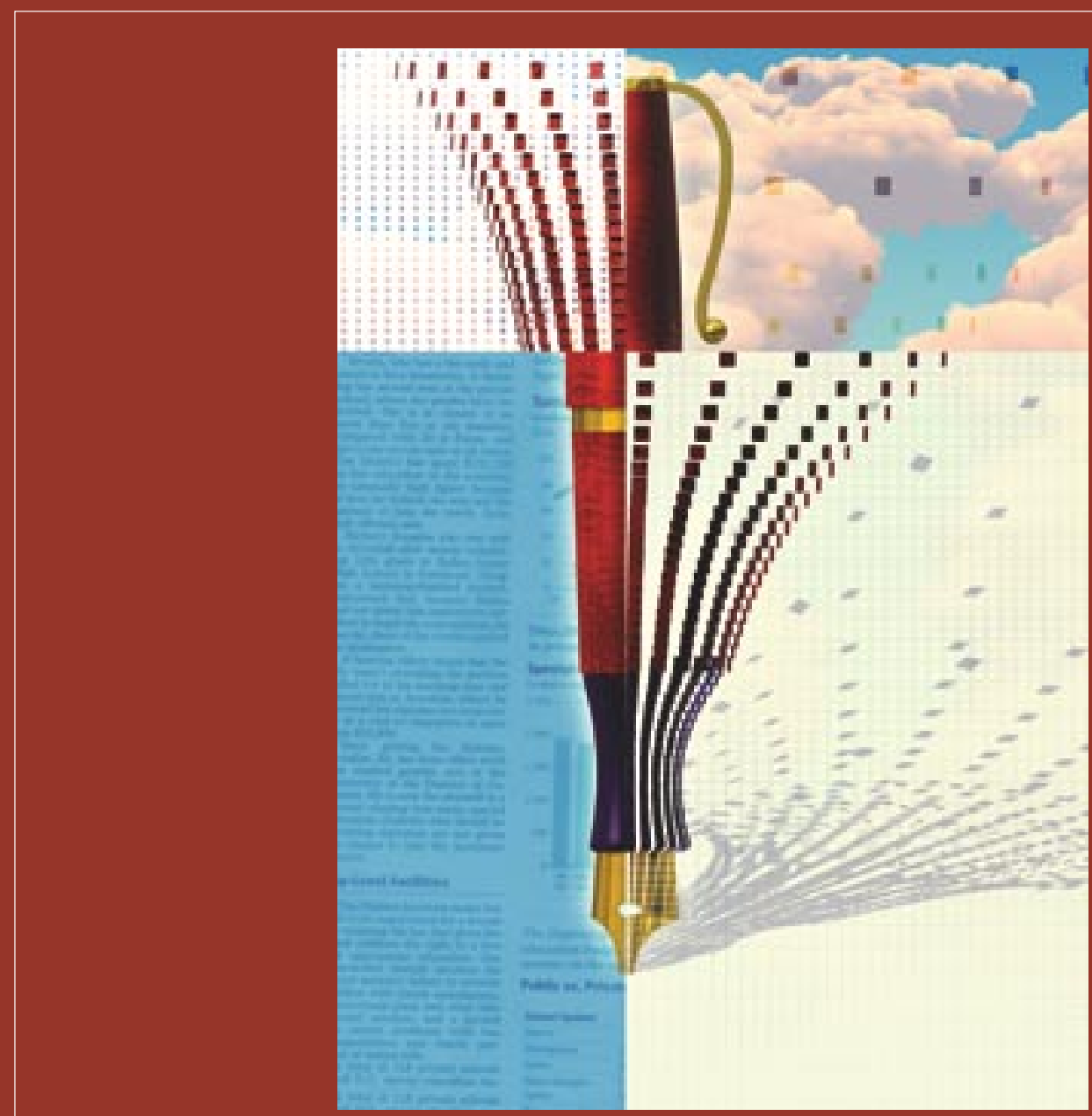

\section{H a n d b o}

\section{Independent Journalis m}

$$
\text { by Deborah Potter }
$$

Deborah Potter is executive director of NewsLab (www.newslab.org), an online resource center for journalists in Washington, D.C., that she founded in 1998. She has taught journalism as a faculty member at The Poynter Institute and at American University, and is a past executive director of the Radio and Television News Directors Foundation. Potter leads workshops for journalists in newsrooms across the United States and around the world. She is a featured columnist writing about broadcast news for American Journalism Review and the author of Ready, Set, Lead: A Resource Guide for News Leaders. Potter spent more than 20 years in TV news, including 16 as a network correspondent for CBS News and CNN, covering the White House, State Department, Congress, national politics, and environmental issues. She also hosted the PBS TV series "In the Prime." She has a BA from the University of North Carolina at Chapel Hill and a master's degree from American University. 


\section{Contents}

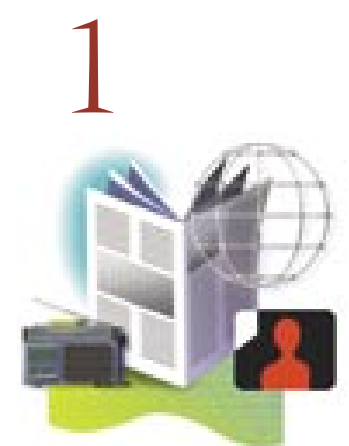

What Is News?

[4]

Types of news

Where the news comes from

The journalist's role

Objectivity and fairness News providers
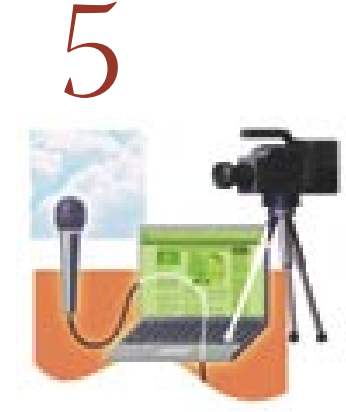

\section{Broadcast and Online}

Broadcast story forms and terms

Broadcast writing

Sound

Pictures

Newscasts

Online news

Online story forms

Online writing
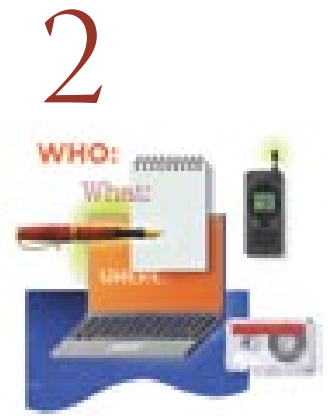

Getting the Story

Five W's and an $\mathrm{H}$ Observation

Research

Sources

Interviews

Ground rules

Getting it right
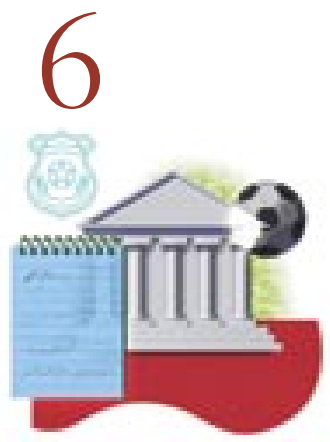

Specialized Journalism

[46]

Beat reporting skills

Government and politics

Business and economics

Health, science, and the

environment

Police and courts

Sports

Questions journalists

should ask about polls
3

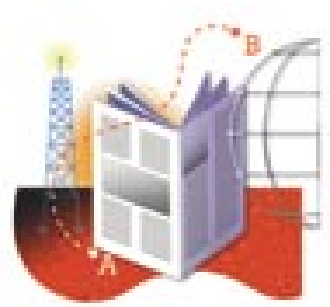

Telling the Story

[22]

Focus

Writing

Leads

Story structure

Endings

Attribution

Quotes and sound bites Numbers
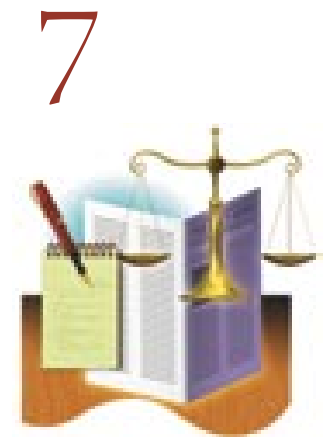

Ethics and Law [54]

Ethical principles

Ethical decision-making

Ethics codes

Codes of conduct

Community standards Legal issues
4

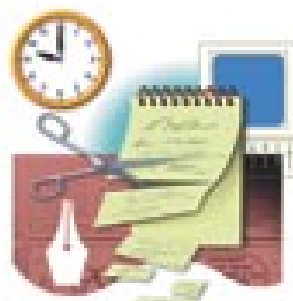

Editing the Story

[30 ]

Newspaper jobs

Broadcast jobs

The editor's role

Copy editing

Coaching

Headlines, captions, and teases

Graphics and visuals

Supervising

8

\section{Journalism \\ Resources}

Membership groups Reporting and editing Specialized journalism Journalism training Freedom of expression Books

Ethics codes 


\section{INTRODUCTION}

Journalism is both a profession and a craft, since journalists draw on specialized skills and adhere to common standards. So what makes journalism different from other occupations like medicine or law, which could be described in similar terms? Perhaps the greatest difference is the special role the news media play in a free society.

A free press has often been called the oxygen of democracy, because one cannot survive without the other. The French political writer Alexis de Tocqueville noted as much when he visited the United States almost 200 years ago. "You can't have real newspapers without democracy, and you can't have democracy without newspapers," he wrote. Since then, that simple statement has been proven true in nations all over the world. Democracies, established or emerging, depend on the consent of an informed citizenry, and the news media are a primary source of the information people need in order to govern themselves.
To ensure that journalists are able to provide that information, many countries have established legal protections for a free press. In the United States, for example, journalism is the only profession mentioned in the Constitution, which states: "Congress shall make no law ... abridging the freedom of speech or of the press." As Thomas Jefferson, the third president of the United States, wrote in 1787, "The basis of our government being the opinion of the people, the very first object should be to keep that right; and were it left to me to decide whether we should have a government without newspapers, or newspapers without a government, I should not hesitate a moment to prefer the latter."

Journalists in a free society not only have certain legal protections, they also have responsibilities. In some countries, these responsibilities are spelled out and in others they are implicit. But in almost every case they amount to the same thing: to keep citizens informed, journalists have a responsibility to provide information that is accurate and reported fairly - and independently - from outside influences. 
"The central

purpose of

journalism is to

provide citizens

with accurate

and reliable

information they

need to function in

a free society."
This handbook offers a brief introduction to the fundamentals of journalism as it is practiced in democratic systems - a journalism that attempts to base itself on fact and not opinion. Opinions have their place, but in the best-edited newspapers they are confined to the editorial pages and op-ed (guest writer) columns. It is the kind of journalism I practiced myself for more than 20 years as a reporter and editor, and that I now teach in professional workshops in the United States and around the world. My goal is to provide a useful and practical guide that will help all journalists do better work for the communities they serve.
In democratic societies around the world, the news media have come to serve an additional function as watchdogs on the activities of the political and judicial branches of government. They have kept democracies viable by giving voice to the voiceless, ensuring that a ruling majority cannot trample the rights of a minority. A 19th century American writer and humorist, Finley Peter Dunne, once said that a journalist's job is "to comfort the afflicted and afflict the comfortable.” But the primary role of journalism in a free society has remained the same for generations. When a U.S.-based group, the Committee of Concerned Journalists, surveyed journalists about the character of their profession at the very end of the 20th century, they came to this common understanding: "The central purpose of journalism is to provide citizens with accurate and reliable information they need to function in a free society."

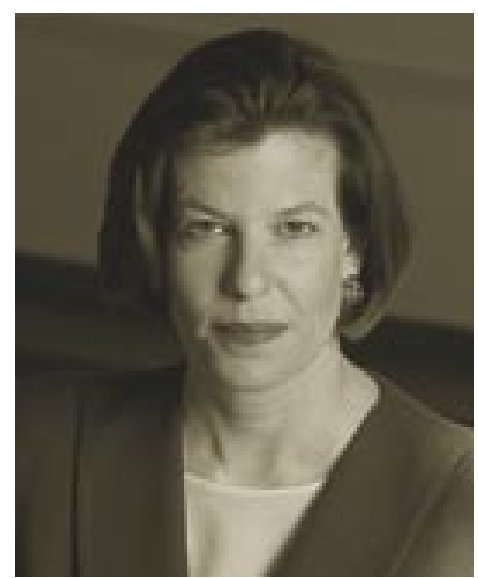

Deborah Potter 
WHAT IS NEWS?

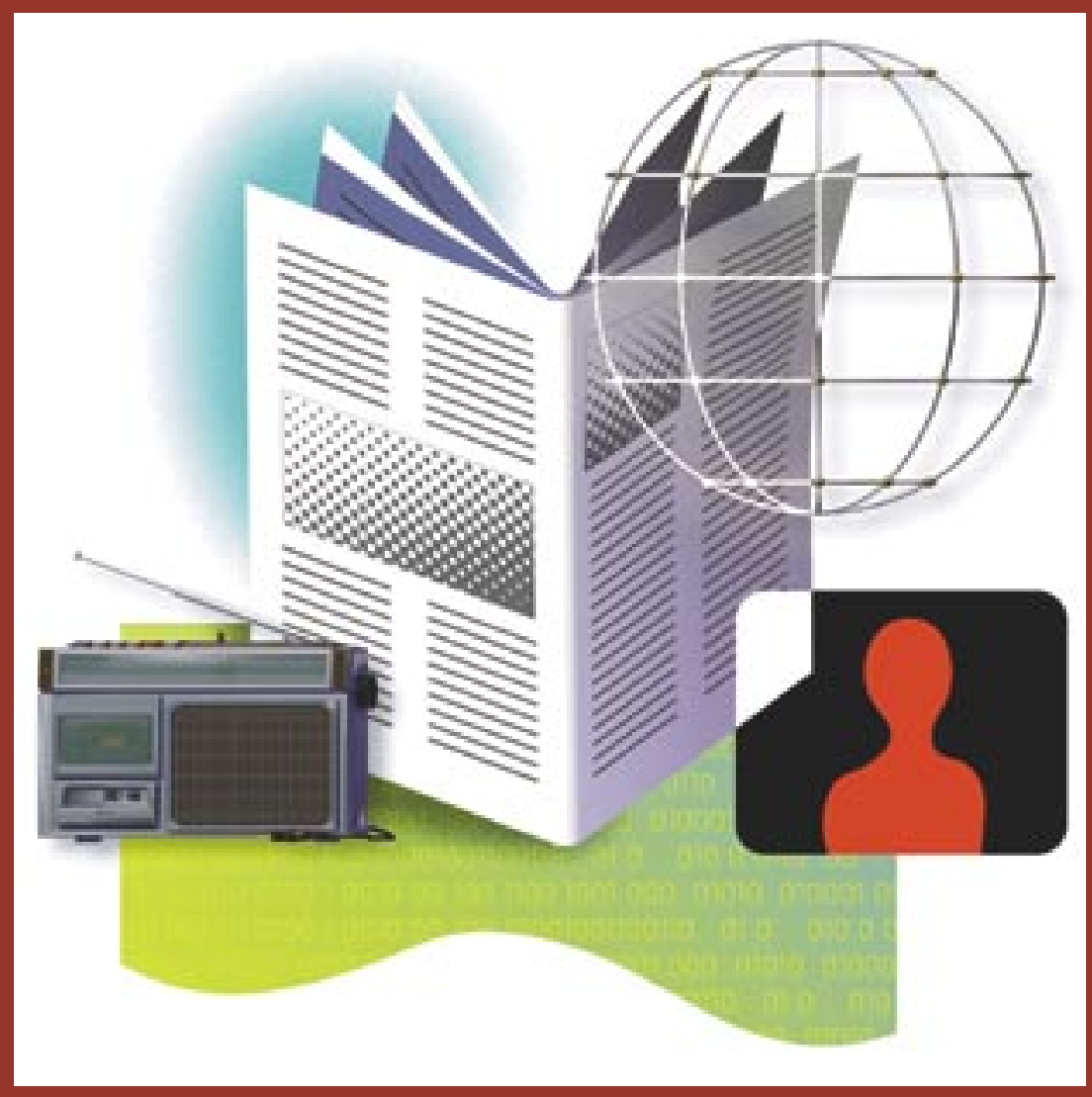


The answer to the question "What is news?" may seem obvious.

News is what is new; it's what's happening. Look it up in the dictionary, and you'll find news described as "a report of recent events or previously unknown information." But most of the things that happen in the world every day don't find their way into the newspaper or onto the air in a newscast.

So what makes a story newsworthy enough to be published or broadcast? The real answer is, it depends on a variety of factors. Generally speaking, news is information that is of broad interest to the intended audience, so what's big news in Buenos Aires may not be news at all in Baku. Journalists decide what news to cover based on many of the following "news values":

\section{Timeliness}

Did something happen recently or did we just learn about it? If so, that could make it newsworthy. The meaning of "recently" varies depending on the medium, of course. For a weekly news magazine, anything that happened since the previous edition the week before may be considered timely. For a 24-hour cable news channel, the timeliest news may be "breaking news," or something that is happening this very minute and can be covered by a reporter live at the scene.

\section{Impact}

Are many people affected or just a few?

Contamination in the water system that serves your town's 20,000 people has impact because it affects your audience directly. A report that 10 children were killed from drinking polluted water at a summer camp in a distant city has impact too, because the audience is likely to have a strong emotional response to the story. The fact that a worker cut a utility line is not big news, unless it happens to cause a blackout across the city that lasts for several hours.

\section{Proximity}

Did something happen close to home, or did it involve people from here? A plane crash in Chad will make headlines in N'Djamena, but it's unlikely to be front-page news in Chile unless the plane was carrying Chilean passengers.

\section{Controversy}

Are people in disagreement about this? It's human nature to be interested in stories that involve conflict, tension, or public debate. People like to take sides, and see whose position will prevail. Conflict doesn't always entail pitting one person's views against another. Stories about doctors battling disease or citizens opposing an unjust law also involve conflict.

\section{Prominence}

Is a well-known person involved? Ordinary activities or mishaps can become news if they involve a prominent person like a prime minister or a film star. That plane crash in Chad would make headlines around the world if one of the passengers were a famous rock musician.

\section{Currency}

Are people here talking about this? A government meeting about bus safety might not draw much attention, unless it happens to be scheduled soon after a terrible bus accident. An incident at a football match may be in the news for several days because it's the main topic of conversation in town. 


\section{Oddity}

Is what happened unusual? As the saying goes, "If a dog bites a man, that is not news. But if a man bites a dog, it's news!" The extraordinary and the unexpected appeal to our natural human curiosity.

What makes news also depends on the makeup of the intended audience, not just where they live but who they are. Different groups of people have different lifestyles and concerns, which make them interested in different types of news. A radio news program targeted at younger listeners might include stories about music or sports stars that would not be featured in a business newspaper aimed at older, wealthier readers. A weekly magazine that covers medical news would report on the testing of an experimental drug because the doctors who read the publication presumably would be interested. But unless the drug is believed to cure a well-known disease, most general-interest local newspapers would ignore the story. The exception might be the newspaper in the community where the research is being conducted.

News organizations see their work as a public service, so news is made up of information that people need to know in order to go about their daily lives and to be productive citizens in a democracy. But most news organizations also are businesses that have to make a profit to survive, so the news also includes items that will draw an audience: stories people may want to know about just because they're interesting. Those two characteristics need not be in conflict. Some of the best stories on any given day, in fact, are both important and interesting. But it's fairly common for news organizations to divide stories into two basic categories: hard news and soft news, also called features.

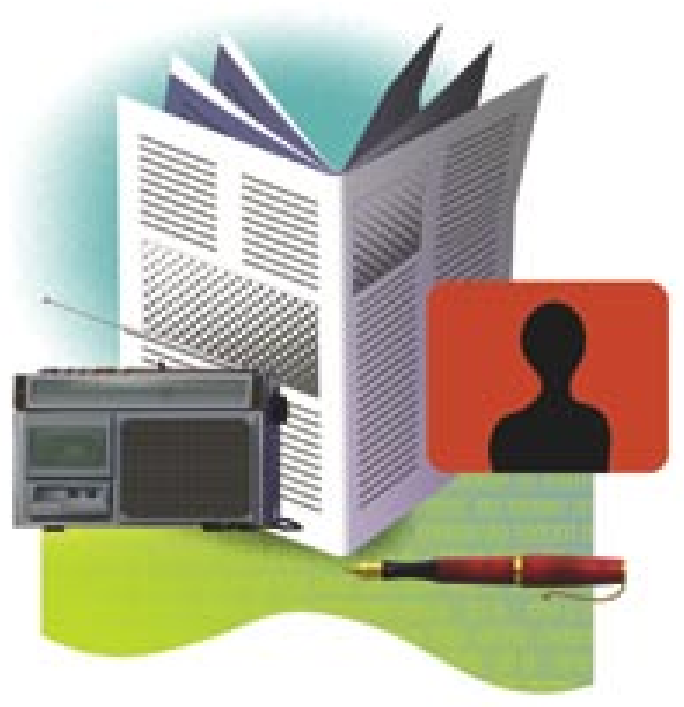

\section{Types of News}

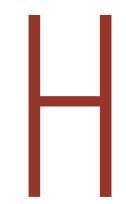

ard news is essentially the news of the day. It's what you see on the front page of the newspaper or the top of the Web page, and what you hear at the start of a broadcast news report. For example, war, politics, business, and crime are frequent hard news topics. A strike announced today by the city's bus drivers that leaves thousands of commuters unable to get to work is hard news. It's timely, controversial, and has a wide impact close to home. The community needs the information right away, because it affects people's daily lives.

By contrast, a story about a world-famous athlete who grew up in an orphanage would fit the definition of soft news. It's a human-interest story involving a prominent person and it's an unusual story that people likely would discuss with their friends. But there's no compelling reason why it has to be published or broadcast on any particular day. By definition, that makes it a feature story. Many newspapers and onlinenews sites have separate feature sections for stories about lifestyles, home and family, the arts, and entertainment. Larger newspapers even may have weekly sections for specific kinds of features on food, health, education, and so forth. 
Topic isn't the only thing that separates hard news from features. In most cases, hard news and soft news are written differently. Hard news stories generally are written so that the audience gets the most important information as quickly as possible. Feature writers often begin with an anecdote or example designed primarily to draw the audience's interest, so the story may take longer to get to the central point.

Some stories blend these two approaches. Stories that are not time-sensitive but that focus on significant issues are often called "news features." A story about one community's struggle to deal with AIDS, for example, is a news feature. A story about a new treatment option for AIDS patients would be hard news. News features are an effective way to explore trends or complex social problems by telling individual human stories about how people experience them. (We'll discuss these different writing styles in more detail in Chapter 3, "Telling the Story.")

\section{Where the News Comes From}

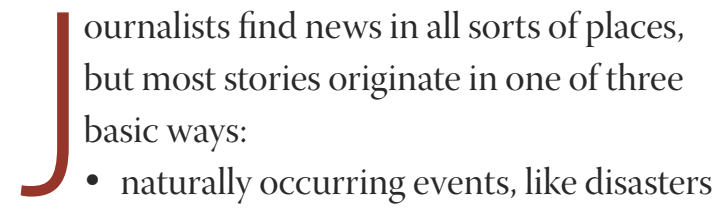
and accidents;

- planned activities, like meetings and news conferences;

- reporters' enterprise.

Unplanned events frequently become major news stories. A ferry sinking, a plane crash, a tsunami, or a mudslide is newsworthy not just when it happens but often for days and weeks afterwards. The extent of the coverage depends in part on proximity and who was involved. A fatal automobile accident in Paris might not be big news on any given day. But an accident in Paris in 1997 was a huge news story, not just in France but also around the world, because one of the victims was Britain's Princess Diana.

Citizens who witness a disaster will often contact a news organization. Journalists also learn about these events from first responders: police, fire, or rescue officials. In some countries, news organizations are able to monitor emergency communications between first responders and can dispatch journalists to the scene quickly so they can watch the story unfold.

In many newsrooms, the most obvious source of news is the daily schedule of events in town, which includes government meetings, business openings, or community events. Often called a "daybook," this list of activities is not automatically newsworthy but it provides a good starting point for reporters searching for news. Reporters who regularly cover specific kinds of issues or institutions, also called "beat" reporters, say they often get story ideas by looking at agendas for upcoming meetings.

Press releases can be another source of news, but again, they are just a starting point. Dozens of press releases arrive in newsrooms every day, by mail, by fax, or even on video via satellite. Government officials and agencies generate many of them, but other large organizations like private businesses and nonprofit groups also issue press releases to let the news media know what they are doing. A press release may resemble a news story but because it is produced by someone with a vested interest in the subject it is not likely to tell the complete story. Press releases may be factually correct, but they usually include only those facts that reflect positively on the person or organization featured in the release. Even if a press release looks newsworthy, a professional journalist first must verify its authenticity, and then begin asking questions to determine the real story before deciding if it's worth reporting.

Staged events, such as demonstrations, also can produce news, but journalists must be wary of being manipulated by the organizers who want to tell only their side of the story. Politicians have become adept at staging events and "photo opportunities" in order to attract coverage, even when they have no real news value. That does not mean journalists should ignore these events, but only that they need to do additional reporting to get a complete story. 
Most reporters say their best stories come from their own enterprise. Sometimes story suggestions come from strangers, who may visit, telephone, or e-mail the newsroom with a complaint or concern. Some news organizations actively solicit ideas from people who live in the communities they serve, by providing a telephone number or an e-mail address where suggestions can be submitted. Journalists spend a lot of time building relationships with people who can provide them with information. (We'll talk more about source building in Chapter 2, "Getting the Story.")

Journalists frequently find stories simply by looking around and listening to what people are talking about. What you overhear at a sports event or in line at the post office could turn into a news story. Ask the people you meet when you are not covering a story what is going on in their lives or their neighborhoods and you might find yourself on the trail of a news story no one else has covered.

Another way to find news is to ask what has happened since the last time a story was in the paper or on the air. Follow-ups often lead to surprising developments that are even more newsworthy than the original report. For example, a story about a fire the day after it happened might tell you how many people were killed and the extent of the property damage. But a follow-up several weeks later could discover that a faulty radio system made it impossible for firefighters to respond quickly enough to save more lives.

Documents, data, and public records can lead to terrific stories as well. Reporters can use them to look for trends or to spot irregularities. This kind of work requires more effort, but the results are almost always worth the trouble. It's considerably easier when the data are made available electronically, of course, but reporters have been known to enter data from paper records into computer database programs just so they can search for the most significant information in a pile of statistics. For example, a list of people who have received speeding tickets might yield a story if it could be sorted by name instead of date. That's how television reporter Nancy Amons learned that one driver in her town had managed to amass a dozen traffic violations in three years and had even caused an accident that killed another driver without ever losing his driver's license. When she investigated, city officials admitted they had failed to do their job.

\section{The Journalist's Role}

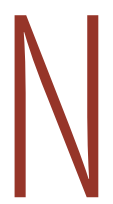
ew technologies have made it possible for anyone with a computer to disseminate information as widely as the largest news organizations. But a well-designed Internet site, no matter how well it's written or how often it's updated, is not necessarily a reliable source of news. The truth is that in a complex world where information is no longer a scarce commodity, the role of the journalist has become more important than ever.

Unlike a propagandist or a gossip, the journalist sorts through the information available and determines how much of it is valuable and reliable before passing it on to the public. News stories, whether hard news or features, must be accurate. Journalists not only collect the information they need to tell the story, they have to verify the information before they can use it. Journalists rely on first-hand observation whenever possible and consult

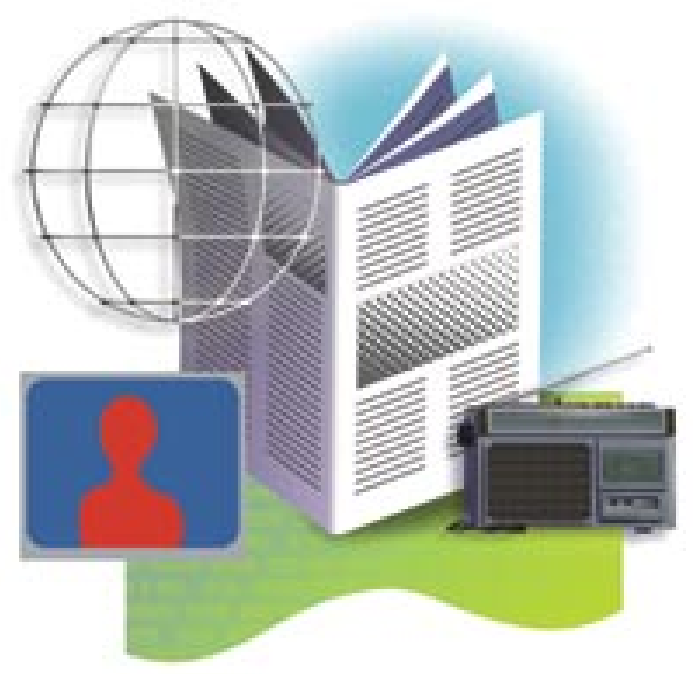




\section{In a complex world}

\section{where information}

is nolonger a scarce

commodity, the role of the journalist

has become more

important than ever.

multiple sources to make sure the information they receive is reliable. And, except on rare occasions, they identify the sources of their information so the audience can evaluate its credibility.

But journalism is more than just the distribution of fact-based information. Propaganda also may be based on facts, but those facts are presented in such a way as to influence people's opinions. As we've already noted, public relations professionals use facts, as well, but may tell only one side of a story. Journalists, on the other hand, strive to be fair and complete. They strive to tell an accurate and authentic story, one that reflects reality, not their own perception of it or anyone else's.

Another distinction between journalism and other forms of information is that journalists strive for independence from the people they cover. A public relations professional who is employed by the organization he or she is writing about is unlikely to include information that might make the organization look bad. A journalist, on the other hand, will attempt to provide a complete picture, even if it is not entirely positive.

Journalists are not mere transmission belts for their own viewpoints or for information provided by others. They do original reporting, they do not confuse fact with opinion or rumor, and they make sound editorial decisions. A principal responsibility of journalism, says Bill
Keller, executive editor of The New York Times, is "applying judgment to information."

Unlike other purveyors of information, journalists owe their primary allegiance to the public. As Canada's Montreal Gazette states in its code of ethics, "A newspaper's greatest asset is its integrity. Respect for that integrity is painfully won and easily lost." To maintain that integrity, journalists work hard to avoid conflicts of interest, real or perceived. (We'll talk more about that in Chapter 7, "Ethics and Law.")

\section{Objectivity and Fairness}

T he concept of objectivity in journalism developed almost a century ago, as a reaction to the sensational, opiniondriven reporting that was common in most newspapers of the day. The term "objectivity" was originally used to describe a journalistic approach or method; journalists would seek to present the news in an objective way, without reflecting any personal or corporate bias.

Over time, objectivity was required from the journalists themselves. The executive editor of the American newspaper The Washington Post, Leonard Downie, took the concept so seriously that he refused to register to vote. But many journalists today concede that total objectivity is impossible. In 1996, the U.S. Society of Professional Journalists dropped the word "objectivity" from its code of ethics. Journalists are human beings, after all. They care about their work and they do have opinions. Claiming that they are completely objective suggests that they have no values. Instead, journalists have largely agreed that they must be aware of their own opinions so they can keep them in check. The audience should not be able to tell from the story what the journalist's opinion is. By using an objective, scientific method for verifying information, journalists can report stories that do not reflect their own personal views. The story itself, in other words, should be impartial and fair. 
Journalists also strive to be fair in their reporting by not telling one-sided stories. They look for contrasting views and report on them without favoring one side or another. In addition to verifying assertions of fact, they will seek out differing opinions in cases where the facts are in dispute.

Fairness is not the same thing as balance, however. Balance suggests that there are only two sides to any story, which is rarely the case, and that each side should be given equal weight. Journalists who seek that kind of artificial balance in their stories actually may produce coverage that is fundamentally inaccurate. For example, the vast majority of independent economists may agree on the consequences of a particular spending policy while a small handful has a different opinion, which has been proven wrong by past experience. A story giving equal time or space to the views of both groups would be misleading.

The challenge for journalists is to report all significant viewpoints in a way that is fair to those involved and that also presents a complete and honest picture to the audience. "Fairness means, among other things, listening to different viewpoints, and incorporating them into the journalism," says reporter and blogger Dan Gillmor. "It does not mean parroting lies or distortions to achieve that lazy equivalence that leads some journalists to get opposing quotes when the facts overwhelmingly support one side."

\section{News Providers}

ournalists the world over share certain characteristics. They are curious and persistent. They want to know why things happen and they don't take no for an answer. They are not intimidated by the powerful and they care deeply about the work they do. Kevin Marsh, an editor at the British Broadcasting Company's (BBC) Radio 4, says a good journalist has "the ability to grasp the big truths - with the humility to let them go again when the facts don't fit." A journalist's job is challenging and complicated. As Philip Graham, late chairman of the board of the Washington Post Company, once said, "(A journalist has the) inescapably impossible task of providing every week a first rough draft of a history that will never be completed about a world we can never understand."

Journalists today have more outlets for their work than at any other time in history, from small community newspapers to worldwide television news channels and online-news sites. Each of the media outlets has different strengths and weaknesses.

In most countries, daily newspapers generally have the largest staffs and offer more depth on a wider range of topics than the broadcast media. With the addition of online sites, many newspapers have begun to overcome the limitations of their traditional once-a-day publication schedule. But they largely reach only a literate, affluent audience, people who can read and who have enough money to buy the newspaper or have access to a computer to read it on line.

Radio, one of the most widely used sources of news in the world, has the advantage of speed and easy availability. Radio journalists can get the news on the air quickly and anyone with a battery-powered radio can hear the news almost anywhere at any time. Radio reporters tell stories with sound as well as words, so listeners feel they have experienced some of what the event was really like. Radio news is on the air many times a day, so it is frequently updated. But most radio stations provide only a limited amount of time for each newscast, which tends to be a short summary of only the biggest stories, without the depth or breadth that a newspaper can offer.

With both sound and pictures, television newscasts can show viewers what is happening, not just tell them about it. One of television's strengths is its ability to convey emotion and share experiences with viewers. Technological advances - smaller cameras, digital editing, and mobile uplinks - have made it possible for television to be almost as fast as radio in getting a story on the air. But the medium's dependence 
on pictures can be a drawback: Television news sometimes avoids telling complicated stories because they are not visually compelling.

Recently, the distinction between the traditional categories of print and broadcast news has blurred. In the United States and other countries, many news organizations now produce news in a variety of media, including the Internet. Since the Internet is infinitely expandable, online news is not necessarily subject to the same restrictions of space and time imposed on the print and broadcast media. News sites can provide more information and keep it available for a longer time. And they can make it possible for users to search for the news that most interests them.

Online-news sites affiliated with newspapers, radio, and television stations may look very similar. They illustrate their stories with photographs, and many offer streaming video of stories or complete newscasts. They also may supply a "podcast" version, publishing their files to the Internet so that their subscribers can download the files onto a computer or portable media player for later consumption. On some sites, you can read the text of a story or listen as the writer reads it to you. News organizations are even posting their own Web logs (commonly known by the shorthand term "blogs"), letting journalists write online diaries about the stories they're covering or the decisions being made in the newsroom.

In this evolving world of news, many journalists find they need additional skills to do the job that is expected of them. Reporters may be expected to shoot photographs for use on the Internet, in addition to interviewing sources and writing stories for the newspaper. Editors may be asked to post stories on the Internet, in addition to checking reporters' copy and writing headlines. Photographers may need to shoot video as well as still pictures, and they also may have to provide text to go along with their pictures. Many news organizations are providing training for journalists who are taking on new roles in the newsroom. And some journalism educators are now implementing what they call a "convergence curriculum" to help students learn the multiple skills they may need in the future.

But for all these new demands, the heart of good journalism remains the same. As Bill Kovach and Tom Rosenstiel write in their book, The Elements of Journalism: What Newspeople Should Know and the Public Should Expect, there are some clear principles that journalists in a democratic society agree on and that citizens have a right to expect:

- Journalism's first obligation is to the truth.

- Its first loyalty is to citizens.

- Its essence is a discipline of verification.

- Its practitioners must maintain an independence from those they cover.

- Journalism must serve as an independent monitor of power.

- It must provide a forum for public criticism and compromise.

- It must strive to make the significant interesting and relevant.

- It must keep the news comprehensive and proportional.

- Its practitioners must be allowed to exercise their personal conscience.

These values distinguish journalism from all other forms of communication. Abiding by them is not easy. Journalists face pressure to compromise on these standards almost every day. But keeping them in mind is the best way to ensure that journalism can serve its primary function, supplying citizens with the information they need to make decisions about their lives. 
GETTING THE STORY

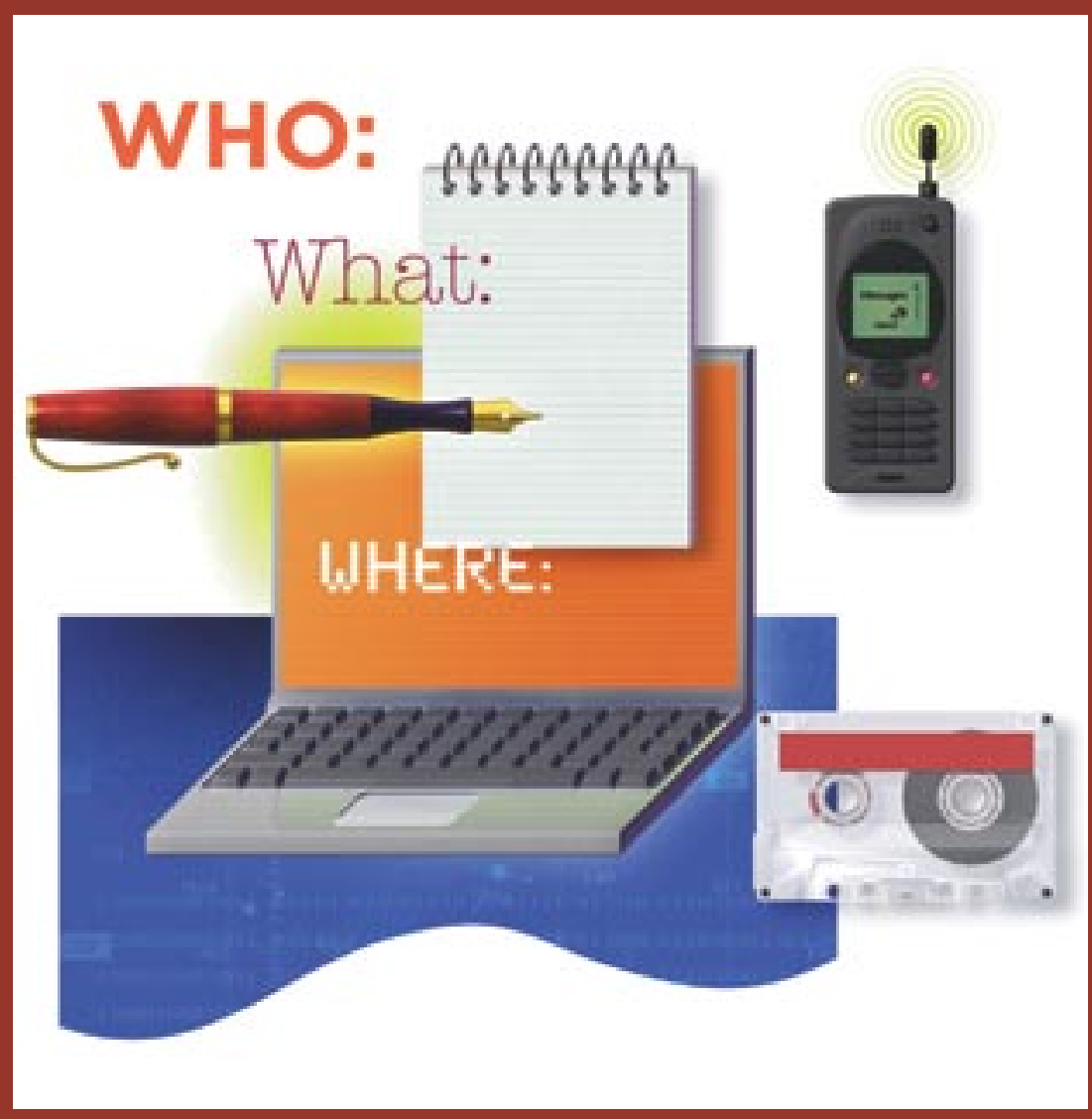




\section{The tip came in an e-mail from a former government official}

\section{who suggested looking into the supply of life rafts on ferries in Washington state. Reporter Eric Nalder, then with the Seattle Times, decided to check it out. His first phone call was to the ferry system's safety director, who was new on the job,}

but who gave Nalder the name and location of his predecessor. When the reporter reached the retired director by phone, he confirmed the shortage of life rafts. Far from being satisfied that he had uncovered a good story, Nalder was just getting started.

To get the full story, Nalder needed documents showing the number of life rafts on every ferry, the capacity of each raft, and the maximum number of passengers each ferry could carry. He had to analyze the data to determine the seriousness of the shortage. He also wanted to ride the ferries and talk to passengers and crew. Only then was he ready to write his front-page story, which revealed that ferries in his state had only enough life rafts to evacuate one passenger out of seven.

Reporting is a painstaking process that involves collecting facts and checking them carefully for accuracy. Journalists sometimes witness stories first-hand, but more typically they learn the details from others who have experienced something directly or who are experts in the topic. That information is reinforced or corroborated by additional sources, and checked against documentary evidence in public records, reports, or archives.

The information a journalist collects should answer questions that are commonly known as the five W's and an H: who, what, where, when, why, and how. Depending on the complexity of the story, a reporter might ask those questions in several different ways.

\section{WHO:}

- Who is involved in this story?

- Who is affected by it?

- Who is the best person to tell the story?

- Who is missing from this story? Who has more information about this?

- Who is in conflict in this story? Do they have anything in common?

- Who else should I talk to about this?

\section{WHAT:}

- What happened?

- What is the point of this story? What am I really trying to say?

- What does the reader, viewer, or listener need to know to understand this story?

- What surprised me? What is the most important single fact I learned?

- What is the history here? What happens next?

- What can people do about it?

\section{WHERE:}

- Where did this happen?

-Where else should I go to get the full story?

- Where is this story going next? How will it end?

\section{WHEN:}

- When did this happen?

- When did the turning points occur in this story?

- When should I report this story? 


\section{WHY:}

- Why is this happening? Is it an isolated case or part of a trend?

- Why are people behaving the way they are? What are their motives?

- Why does this story matter? Why should anyone watch, read, or listen to it?

- Why am I sure I have this story right?

\section{HOW:}

- How did this happen?

- How will things be different because of what happened?

- How will this story help the reader, listener, or viewer? The community?

- How did I get this information? Is the attribution clear?

- How would someone describe this story to a friend?

Many reporters use mental checklists like this one to make sure they have covered all of the important elements of a story.

\section{Observation}

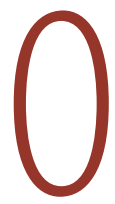

n-the-scene observation is one of the fundamentals of good reporting. Journalists want to witness events for themselves whenever possible so they can describe them accurately to the audience. Good reporters use all of their senses on the scene. They look, listen, smell, taste, and feel the story so the audience can, too.

To do this well, journalists need an accurate record of their observations. A print reporter can do his or her job with a notebook and a pencil or pen, but many also carry audio recorders and cameras, especially if they are expected to file stories for an online edition as well. For radio, journalists need to capture sound, and for television, both sound and video.

\section{Good reporters}

\section{use all of their}

senses on

the scene.

Using a recorder is one way of making sure that any quotations you might use are accurate. But electronics have been known to fail, so it's important for all journalists to be skilled notetakers. Here are some tips on note-taking from experienced reporters:

- Write down facts, details, thoughts, and ideas. Make clear which is which, and where they came from.

- Draw diagrams of rooms, scenes, or items in relationship to each other.

- Always get correctly spelled names, titles, and contact information. Ask for birth date and year, to make sure you have the person's age right.

- Spell out interview ground rules in the notebook.

- Don't crowd the notebook. Leave space for annotating notes.

- Leave the inside covers blank to write down questions to ask later.

- Annotate the notes as soon as possible.

Many reporters use their own shorthand for common words so they can take notes more quickly. Then they annotate their notes, spelling out abbreviations to avoid any confusion later. They also will mark the most important information they have learned, good quotes they may use in the story, anything they need to follow up on or check for accuracy, and questions that still need to be answered.

It sounds obvious, but reporters must be sure they have the tools they need before heading out to cover a story: notebook, pen, tape or digital recorder, and fresh batteries. There's nothing more embarrassing than 
arriving on the scene only to discover there is no film or tape in the camera, or that the only pen in your pocket is out of ink. Today's journalists often carry additional tools: a mobile telephone and a laptop computer. A few other simple items can be useful, as well. Putting a rubber band around your notebook to mark the next blank page makes it easy to find quickly. A plastic bag will protect your notebook when it rains, so the pages stay dry and the ink doesn't run. A small pair of binoculars will help you see what's going on even if you can't get very close. A calculator will help you convert information like the number of tons of fuel carried by an aircraft into terms more familiar to the audience, in this case, liters or gallons.

\section{Research}

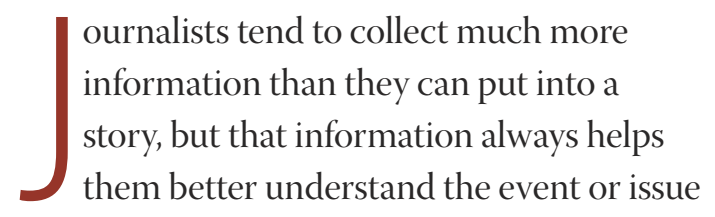
they are covering. Sometimes, background information is essential to give a story deeper meaning. In Eric Nalder's story about life rafts, for example, he included the fact that the water the ferries cross is cold enough in January to kill someone within half an hour. That information

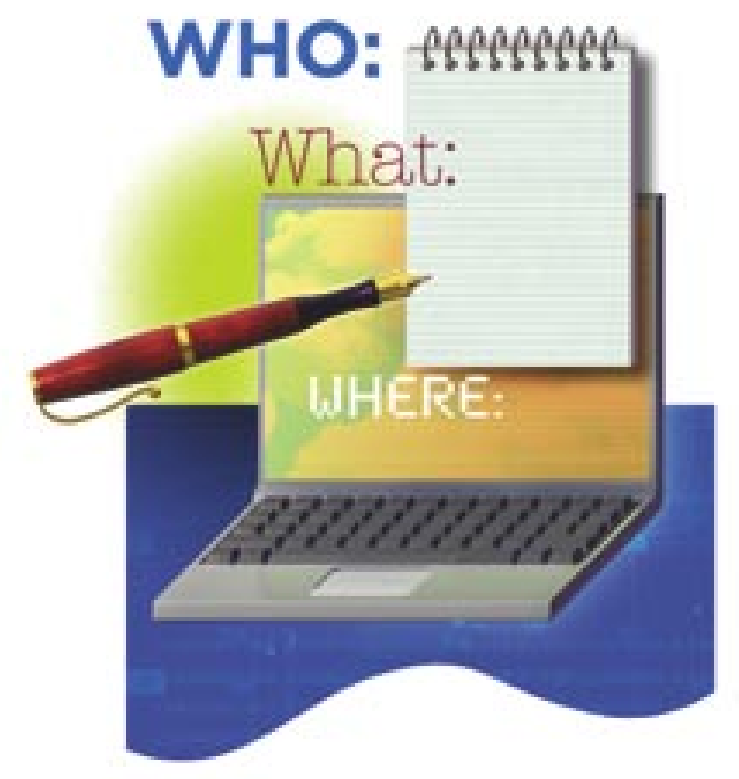

puts the shortage of life rafts in context by explaining more clearly why it matters. It's exactly the kind of information reporters look for when they do research on a story, either before they leave the newsroom or along the way as questions come up.

Journalists have more research tools available today than ever before, thanks to computers and the Internet. Many of them are just high-tech versions of the basic tools of the trade: directories, almanacs, encyclopedias, and maps. Others are databases and reports that would have been much harder to find in the days before the Internet, requiring a personal visit to a library or government building. Still others are resources that few would have imagined two decades ago when the Internet was young: search engines, blogs, chat rooms, and e-mail lists. All of these resources are useful to journalists collecting background on a story. But one of the most basic research tools has not changed in a century: the news organization's own library of previously published or broadcast stories. Whether these "clips" are kept on paper in filing drawers or in computer files, they are a useful starting place for all kinds of stories. Many journalists also keep their own "clip files" of stories they have saved about specific topics.

Imagine that the former president of a neighboring country has died. A reporter assigned to write the story would want to know some basic facts: age, cause of death, and where and when he died. But the journalist would also want information about his time in office, and how the country has changed since he was president. A first step would be to consult previous news reports, either in the newsroom's archive or online. Those reports might mention someone who was close to the former president, whom the reporter could ask for an interview. The reporter would want to have some background on that person before conducting the interview, and might learn that the former president's friend kept all of his letters, which could reveal some surprising new information. 
Doing an interview without having done any background research is like driving to an unfamiliar place without consulting a map. You might get where you intend to go, but it's just as likely that you will miss a turn along the way.

\section{Sources}

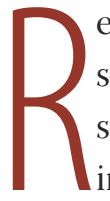
eporters use both primary and secondary sources when reporting news stories. A primary source could be an interview with a person who has direct experience of an event or topic, or an original document related to that topic. The journalist as eyewitness also is considered a primary source. A secondary source might be a written report based on the original document. In the case of a fire, for example, the person whose house burned down would be a primary source. So would a firefighter who had been involved in putting out the fire. But the press release issued by the fire department the next day would be a secondary source.

One rule of thumb reporters follow when researching a story is that no single source can provide all of the information they might need. In the case of the former president, each source the reporter consulted led to another source. Sometimes, sources contradict each other. To clear up discrepancies, reporters may have to see where the weight of the evidence lies or seek out original sources, such as documents, to determine which version is true. Secondary sources are most useful as a way of confirming information acquired from primary sources.

Whatever sources you use to research the background of a story, it's critical to consider the validity or credibility of the source. These days, anyone can design a professional-looking Web site, or arrange to send an e-mail that looks authentic but is really a hoax. Just because you can find it online does not mean that it's true. Journalists need to verify the source of all information to determine whether it's credible enough to use in a news story.

\section{Good reporters}

"work" their

sources regularly,

contacting them

to ask if anything

interesting is

happening.
Deciding what sources to use for a story is a large part of a journalist's job. Here are some useful questions for evaluating whether you have chosen the right source or the best source for your story.

- How does this source know what he or she knows? (Is this person in a position to know these things, either personal or professional?)

- How can I confirm this information through other sources or through documents?

- How representative is my source's point of view? (Is this just one person who complains loudly about the landlord, because they have a personal problem? Or is this the most articulate voice speaking for an entire group of tenants who have serious, legitimate problems?)

- Has this source been reliable and credible in the past?

- Am I only using this source because it's the easy way to go or because I know I'll get something I can use?

- What is the source's motive for providing information? (Is this person trying to make himself look good, or to make his boss look bad? Why is he or she talking to me in the first place?) 
Once you discover a helpful source of information for one story, it's a good idea to stay in touch with that person over the long term. Get as much contact information as possible for every source, not just an office address and telephone number, but mobile and home telephones and e-mail addresses as well. Good reporters "work" their sources regularly, contacting them to ask if anything interesting is happening. Make it easy for sources to get in touch with you, as well, by giving your business card to everyone you meet on a story.

Anyone with access to information, including secretaries and clerks, can be a useful source for a journalist. They can provide copies of documents, and they often know who is the most knowledgeable person on a given topic. A reporter who treats them with respect may find his or her request for an interview with the secretary's supervisor accepted more quickly.

\section{Interviews}

\section{A} merican reporter Kristin Gilger says, "Skillful interviewing is the basis for all good reporting and writing." An interview is defined as information, opinion, or experience shared by a source in conversation with a reporter. What makes an interview a little different from an ordinary conversation is that the reporter determines the direction of the questioning.

Setting up an interview is not always easy. People may not want to talk with a journalist, especially if the story is controversial. When dealing with public officials, start from the premise that the public has a right to know what the officials are doing. Experienced reporters have found they can persuade even the most reluctant officials to agree to an interview by anticipating the excuses and roadblocks they may use.

\section{- They don't have time.}

The reporter can offer to meet at the most convenient time or place for the person they want to speak with. Limiting the amount of time requested also may help.
- They are afraid because they think the story will make them look bad.

Treating people with respect and telling them precisely why you want to talk with them will help sources be less anxious.

\section{- They don't know what to say.}

Reporters need to be clear about why the story needs a particular person's point of view.

- They are hard to reach.

Reporters often have to go through a secretary or public relations officer to contact the person they want to interview. If they suspect that their request is not being forwarded, some reporters will write a letter to the source, or call during lunch or after business hours in an effort to get through.

Once you have secured the interview and researched the person and the topic, there is still more preparation to do. Most reporters develop a list of questions or topics, which they take with them but do not read from during the interview. Instead, they refer to the list only near the end to make sure they haven't forgotten something important. The list also includes other information, documents, or photographs they want to obtain from that source.

Questions are the backbone of an interview. They are the rudder, keeping the ship going in the right direction. Good questions can reward you with unexpected answers, rich information, and surprises. Poor questions can leave you wondering why you bothered to talk to that person anyway. Questions that are too specific can lead you down the wrong trail.

\section{"Skillful interviewing is the basis for}

\section{all good reporting} and writing." 


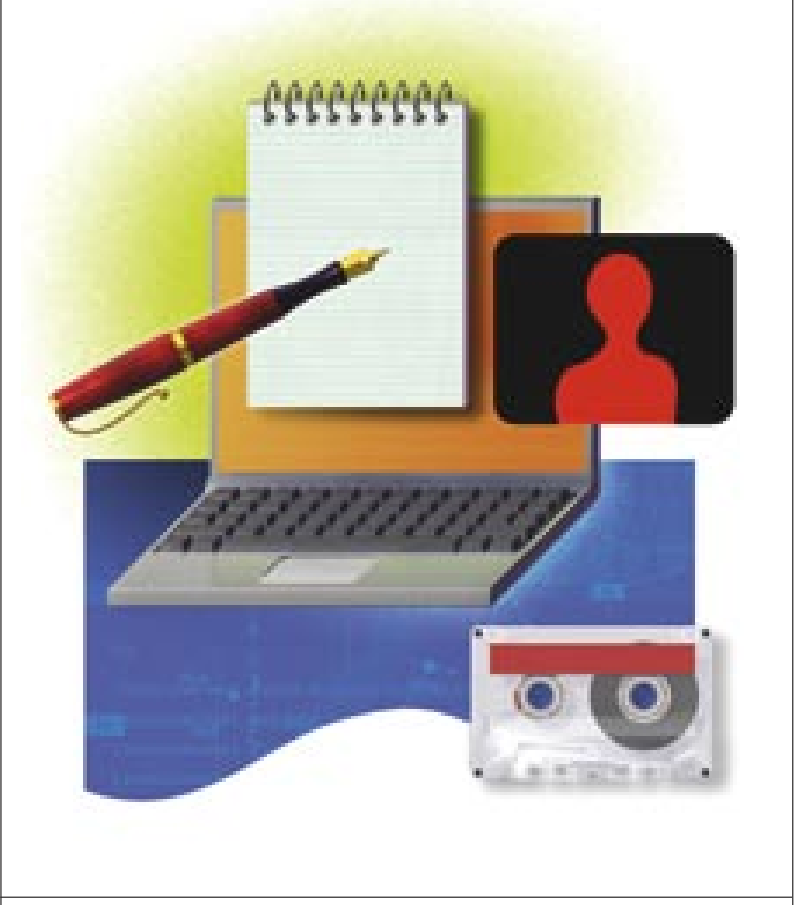

The first question in an interview is important because it sets the tone for what follows. A lot of journalists like to begin with an "ice-breaker" question that lets the source relax. It's something they're comfortable answering. It may, in fact, have nothing to do with the reason you are there. But often it helps to establish your credentials with the source, and that can establish a sense of trust and openness.

Most of the time, the best questions are open-ended questions that cannot be answered with a simple yes or no. They are also nonjudgmental, in that they do not establish the reporter's point of view. It's the difference between, "What do you think about that?" and "What could you have been thinking!" While it's important to ask good questions, it's also important to be quiet and let the interviewee talk. Good journalists are good listeners, and often learn the most significant information by being silent. What you hear also can lead to additional questions that may not have occurred to you.
Robert Siegel, who works for National Public Radio in Washington, D.C., tells the story of an interview he did with a Turkish diplomat after Pope John Paul II was shot and wounded by a Turk in Rome. His first question, "Do you know any details about this man, Mehmet Ali Agca; where he lived in Italy, what he did there, what kind of visa the Italians gave him?" The answers were all no. After several more tries, Siegel paused, about to give up. And the diplomat filled the silence with this, “... except that he is the most famous convicted murderer in Turkey, who escaped from prison after assassinating the editor of one of our major newspapers." Siegel says he almost lost a good story by asking questions that were too narrow. He acknowledges that a better way to open the interview might have been, "Tell me about this man."

Reporters can do interviews in person, by telephone, or online via e-mail or instant messaging. Each approach has advantages and disadvantages. Interviewing in person gives the reporter a more complete sense of the individual. What kinds of photos are on the wall? Is the desk messy or neat? What books are in the bookcase? Meeting in person also gives the reporter the ability to judge the source's credibility based on his demeanor. Does he look nervous or comfortable? Is she willing to look the reporter in the eye?

Christopher (Chip) Scanlan, director of writing workshops for The Poynter Institute, a journalism school in the United States, tells the story of interviewing a woman who lost her husband to cancer. She gave him a tour of her home, and in the bedroom she said, "You know, every night I put just a little of [my husband's] cologne on the pillow, so I can believe he is still with me." It's a detail that the reader can smell and feel, which Scanlan never would have learned over the phone or online.

Telephone interviews take less time, and some reporters find it easier to take good notes when they don't have to worry about maintaining eye contact with the source. They can even type their notes into the computer. E-mail interviews are useful for reaching people 
in distant places, but the reporter can't listen to what's being said and follow up in "real time." Instant messaging via the Internet is more akin to a telephone interview. But both online methods raise the question of whether the person they appear to be from actually sent the answers.

Because of these concerns, The VirginianPilot newspaper in Norfolk, Virginia, has instituted this newsroom policy for online reporting: "In quoting from electronic communications, we will make certain the communication is genuine, as it is easy to fake Internet return addresses or log on as someone else. The Internet is not controlled like a wire service [such as Reuters or the Associated Press]; hoaxes can come from anywhere."

Reporters using e-mail or other online forms of communication should follow the same professional standards as they would in any other form. They must identify themselves as journalists and tell what information they are seeking and why. They need to apply the same fact-checking and thinking skills they would to any other source of information.

No matter which way they conduct an interview, reporters usually have some questions they save for the end. First, they may summarize the conversation to be sure they've heard accurately what was being said. Then they will ask if there is anything else the person being interviewed wants to add. They also ask for the best way to get back in touch with the person, especially after hours, and they thank the person for his or her time. And many journalists have one last question they ask at all interviews, "Who else should I talk to about this?"

\section{Ground Rules}

M ost interviews are conducted "on the record," which means the reporter can use anything that is said and attribute it directly to the person who is speaking. It is important to make sure the source knows this, especially when the reporter is dealing with ordinary people who are not accustomed to being quoted in the newspaper or on the air.

If the information is not to be on the record, both the reporter and the source must agree in advance to the conditions under which the information can be used. An interview "on background" or "not for attribution" generally means the information can be used in a story and the source's words can be quoted directly, although he or she cannot be named. However, the source can be identified in a general way, for example, as "a foreign ministry official" or "a company engineer" - as long as the source and the journalist both agree on the description to be used.

Many news organizations have written policies regarding the use of anonymous sources. The New York Times newspaper, for example, says: "The use of unidentified sources is reserved for situations in which the newspaper could not otherwise print information it considers reliable and newsworthy. When we use such sources, we accept an obligation not only to convince a reader of their reliability but also to convey what we can learn of their motivation." Reporters should not be too quick to agree to talk on background because sources sometimes try to use it as a cover for a personal or partisan attack, knowing it cannot be traced back to them. And using an unnamed source makes it more difficult for the audience to evaluate the credibility of the information.

\title{
the backbone of
}

\author{
an interview.
}


There are times when reporters have to get information on background because it's the only way a source will agree to talk. A source who fears for her safety if others learn that she has spoken to a reporter may agree to provide information only on background. Here are some guidelines for deciding whether to accept and use background information:

- The story is of overwhelming public concern.

- There is no other way to get the information on the record.

- The source is in a position to know the truth.

- You are willing to explain (in your story) why the source could not be named.

In some capitals, government officials will talk to reporters on background as well as "deep background," which means the information can be used but not in a direct quote, and the source cannot be identified. A reporter could write only that officials are known to believe something or another. Information that is offered "off the record" cannot be used at all, so most reporters will fight this arrangement unless the source is so important to the story that they have no other choice. Off-the-record information cannot even be repeated to another source, but it can tip reporters off to a story that is worth pursuing.

Whatever the arrangement, it's up to the reporter to make sure both sides understand and agree to the ground rules before the interview. Sometimes sources try to change the rules in the middle, by telling the reporter something important and then adding, "But you can't use that, of course." That's why it's a good idea to spell things out at the beginning, and not to agree to withhold information unless a separate deal is reached before proceeding with the interview.

\section{Credibility is a}

\section{journalist's most}

important asset,

and accuracy is

the best way to

protect it.
Journalists also should be clear about how far they will go to protect the identity of a source. In some jurisdictions, journalists may risk going to jail if they refuse to reveal information about a confidential source in a court of law. If a journalist is not willing to risk facing time in prison to protect a source, he or she should say so.

Some reporters are quite skilled at getting off-the-record information back on the record. Eric Nalder is one of them. When an off-therecord interview is over, he reads back a quote that is quite innocuous and asks, "Why can't you say that on the record?" When the source agrees, he goes on through his notes, reading back quotes and getting them approved for use. He says he once got an entire interview changed from off the record to on. In part, that's because the source now trusted him to be accurate because he had heard the quotes read back. 
One other ground rule that is important for journalists to understand is the use of an "embargo" on information provided by a source. That means the information is provided on the condition that it is not to be used until a specific time. A government agency announcing a new policy may provide a written summary several hours in advance or even a day ahead. That gives reporters time to digest the information before the press conference making the policy official. Reporters who accept information under an embargo are bound to honor it unless the news becomes public before the specified time.

\section{Getting It Right}

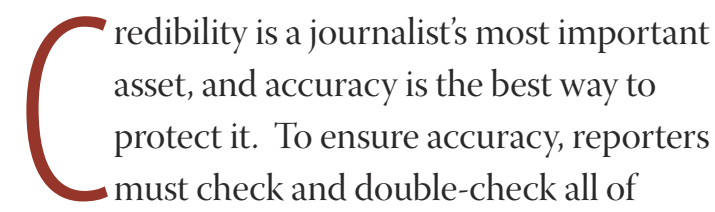
the information they collect for a news story. Reporters will make mistakes, but they should be rare. When an American newspaper, Portland's Oregonian, studied its own errors, editors concluded they happened mainly because of three causes:

- Working from memory;

- Making assumptions;

- Dealing with second-hand sources.

We'll talk more about getting it right in Chapter 4 ("Editing the Story"). But reporters are the news organization's first line of defense against errors. Reporters who take excellent notes and consult them often, and who search for primary sources whenever possible, are better able to abide by the late American publisher Joseph Pulitzer's three rules of journalism: "Accuracy, accuracy, and accuracy."

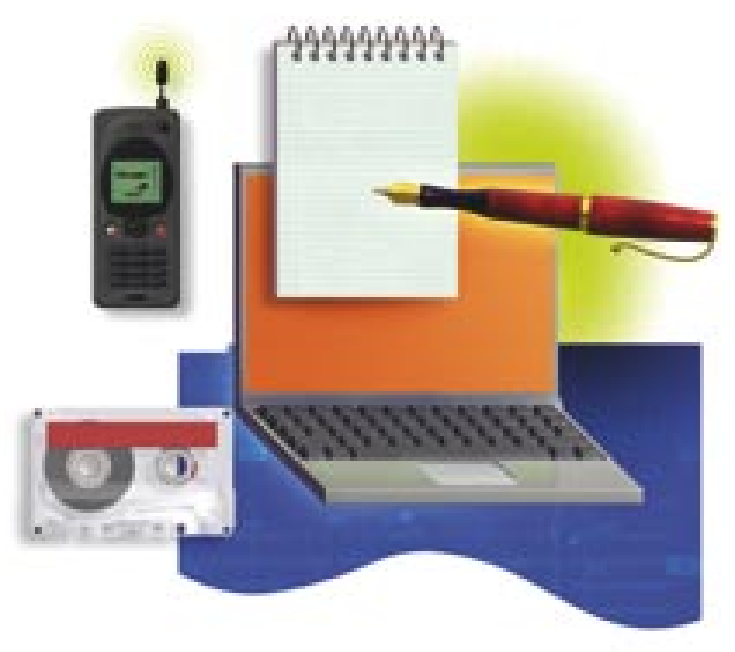




\section{TELLING THE STORY}

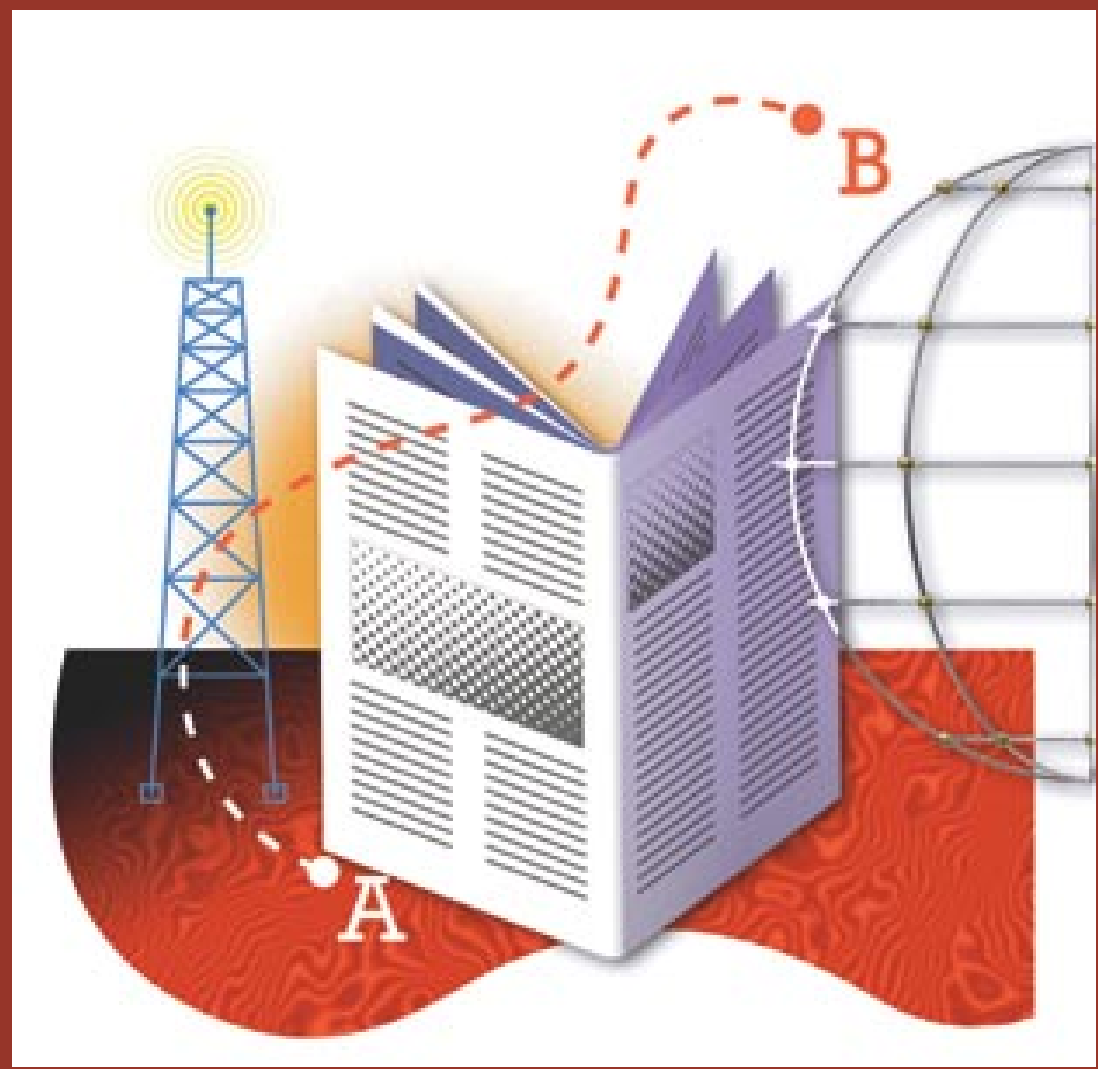


All news stories are made up of facts, observations, quotations, and details. Reporters almost always have more than they

can use, and because they've worked hard to collect all of that information, their natural impulse is to use as much of it as possible in their stories. But cramming in all the facts that will fit rarely results in a well-told story that will engage the audience.

It is harder to understand stories that are overstuffed with information. A reporter who tries to explain everything may succeed only in confusing the audience. Besides, newspapers have only so much space; radio and television news programs only so much airtime; and readers, listeners, and viewers only so much spare time and attention to devote to catching up on the news.

Good journalism involves selection, not compression. Reporters must use their news judgment to decide what is most important to include in a story and in what order to put it. For many reporters, the most difficult part of telling a story is deciding what to leave out. One way to make those decisions is to choose a central point or a theme for the story, also called a focus.

\section{Focus}

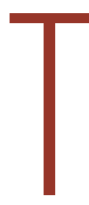
he focus of a story is basically the answer to the question, "What is this story really about?" To determine the focus, Poynter Institute writing instructor Chip Scanlan suggests asking five additional questions:

- What's the news?

- What's the story?

- What's the image?

- How can I tell it in six words?

- So what?

Imagine that you're covering a fast-moving wildfire. You've been out talking to people and observing the damage all day. Now, you need to focus your story before you begin writing. Here's how you might use Scanlan's questions to find your focus:

\section{-What's the news?}

A fire destroyed two houses in the mountains east of the city, but no one was injured and the city business district was spared.

-What's the story?

Two families are homeless but grateful to be alive.

\section{- What's the image?}

Family members hug each other near the smoking ruins of their house.

\section{- How can I tell it in six words or less?}

Fire destroys homes but not spirits.

\section{- So what?}

Property damage from a dangerous fire was limited.

The reporter writing this story now knows that his lead will be about the families who lost their homes; that he'll use a quote high up in the story from a family member expressing gratitude that everyone survived; and that he'll also include general information about property damage. The reporter knows that he can leave out some of the information he collected about the number of fire companies that responded in the business district, but he still might include a quote from the fire chief.

The results of this focus exercise are not meant to suggest that every story has only one acceptable focus. On the contrary, reporters for different news organizations may take the same basic facts and write their stories quite differently because they have decided on a 
different focus. In the case of the wildfire story, a reporter could use the same five questions to come up with a different focus.

\section{-What's the news?}

Businesses in our city escaped damage from a wildfire that destroyed two houses in the mountains east of downtown.

\section{- What's the story?}

Business owners grateful the fire spared them this time.

\section{-What's the image?}

A business owner shakes hands with a firefighter outside his store.

\section{- How can I tell it in six words?}

Fire can't stop business.

\section{- So what?}

Economic impact of a dangerous fire was limited.

This version of the story would lead with the relief of business owners, and use a quote high up from one businessman whose store was spared. Both stories would include the same basic information - that two houses were destroyed while businesses were unaffected - but their emphasis would be different. Knowing what to emphasize before beginning to write helps the reporter decide what facts and quotes to include and what to leave out. As William Zinsser notes in his book On Writing Well, "Clear thinking becomes clear writing; one can't exist without the other."

Experienced reporters don't wait until the end of the day, after they've done all their research, interviews, and observation, before seeking a focus for their story. They may actually start the reporting process with a focus in mind, which helps them decide where to go and whom to interview. Of course, the focus can change as they collect more information, and it often does. The most important thing is for the reporter to have decided on a focus for the story before sitting down to write.

Having a focus in mind is just the first step in planning to write a story. The second is to organize the story so you know what information goes where. Begin by listing the basic facts of the story and decide what should be at the top, at the end, and in the middle.
Select the best quotes or sound bites from your interviews, and decide where they should go in the story. Make note of any details you want to be sure to include. Before they begin to write, some reporters find it useful to create an outline on paper that they use as a kind of road map for the story.

\section{Writing}

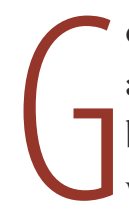
ood news writing is concise, clear, and accurate. That sounds simple enough, but it's actually quite challenging. As we've already mentioned, reporters have a tendency to want to include everything they have learned in their stories. But stories that get to the point are more likely to appeal to busy news consumers, and a news organization that lets stories run on won't have much space or time left to cover other news.

Generally speaking, news stories have shorter sentences and paragraphs than most other types of writing. Each paragraph contains one main idea. A new paragraph begins when a new idea, character, or setting is introduced.

Journalists use simple, direct language that is easy to understand, with more nouns and verbs than adjectives and adverbs. Well-written news stories are not vague, ambiguous, or repetitious, because every word counts. As E.B. White notes in his classic book, The Elements of Style, one of the basic rules of writing is simply this: "Omit needless words."

Good writers always make an effort to choose the most appropriate word to convey what they mean. As the 19th-century American writer Mark Twain said, "The difference between the right word and almost the right word is the difference between lightning and the lightning bug." Reporters routinely consult dictionaries and reference books to make sure the words they choose really mean what they think they do.

Because they write stories for a general audience, journalists also try to avoid jargon - specialized language or technical terms unfamiliar to most people. A hospital spokesman might describe a person as suffering 


\section{Good news writing}

is concise, clear,

and accurate. was unreliable. If the new test is merely faster, the reporter should say so. We'll talk at greater length about accuracy in Chapter 4, "Editing the Story."

\section{Leads}

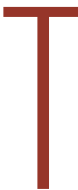

he beginning of a news story is known as the lead. It is meant to capture attention and to draw the reader, listener, or viewer into the story. There are two basic types of leads: hard and soft. A hard lead summarizes the essential facts of the story - the five Ws and an $\mathrm{H}$ discussed in Chapter 2 - while a soft lead may set the scene or introduce a character. Another way to look at the difference between these types of leads is to consider a hard lead as the answer to the question, "What's the news?" and a soft lead as the answer to the question, "What's the story?"

Either type of lead can be used for a hardnews story. For example, a story about the election of a new prime minister could be written one of several different ways. A hard lead might read like this:

Former rebel leader Joshua Smith was elected prime minister tonight, winning more than 80 percent of the vote in the country's first democratic election since 1993.

A soft lead would take a different approach: Growing up in Youngtown, Joshua Smith was a little boy with big dreams. Always small for his age, he says the bigger boys at school bullied him. When he told his grammar school teacher he'd be prime minister some day, she laughed.

No one is laughing now. Smith won yesterday's election with more than 80 percent of the vote, becoming the country's first democratically elected leader since 1993.

As you can see, a hard lead tends to be shorter than a soft lead - often only one sentence long. While soft leads can be longer, every sentence in the lead supports the main point of the story. And both leads include the most newsworthy elements of the story. 
Choosing the right kind of lead depends on many factors, including the importance and timing of the story and the type of news organization, publication, or broadcast involved. Wire services, online-news sites, and radio newscasts that thrive on immediacy generally use hard leads. A weekly news program or magazine is more likely to use a soft lead, on the assumption that most of the audience already would know the central facts of the story.

The most common type of soft lead is the anecdotal lead, similar to the example used in the prime minister story. An anecdote is, by definition, a brief tale; when used as a lead it illustrates or foreshadows the larger story. A story about a social trend might begin with several related anecdotes or examples. On rare occasions, a quotation or a question may be the best way to begin a story. All of these leads also can be described as "delayed" leads, because the reader has to wait for several sentences to find out what the story is really about.

\section{Story Structure}

\section{A} ll stories have a structure in the same way that people have a spine, or, at least, they should! Without a structure, stories would be a jumble of facts with nothing to hold them together. Structure is essential for stories to be understandable and meaningful, but not all stories should be structured in the same way. Good writers choose the most suitable shape for the story they are telling.

\section{Inverted Pyramid}

Many news stories begin with the most newsworthy information, following a traditional story structure developed more than 100 years ago. The "inverted pyramid" form puts the most important information at the top, followed by other information in descending order of importance. This shape is useful when reporting important or breaking news, when timeliness is of the essence. If you are the first to report a significant development, you'll want to tell the audience what has happened right at the top of your story. A report on a massive storm, for example, likely would begin with the death toll and the location of the heaviest damage. Writers who resist using this structure when it is called for may be accused of "burying the lead," making it more difficult for the audience to determine the story's importance.

In the inverted-pyramid structure, information following the lead expands or develops the point that is made in the lead. In the case of the storm report, the writer might describe the scene of the worst devastation, and then include a quote from a survivor or an emergency worker. Supporting paragraphs would elaborate on the topic, filling in details and providing background on the storm. In a longer story, a reporter might include secondary information that is related to the primary theme but not directly. The storm story, for example, could include information about international relief efforts, and the needs of survivors, both immediate and long term. One reason for the popularity of this structure is that editors can cut from the bottom to save space and time without worrying about cutting vital information.

\section{Hourglass}

A modified form of the inverted pyramid is known as the "hourglass" structure. It begins, in a similar fashion, with the most important information - but after a few

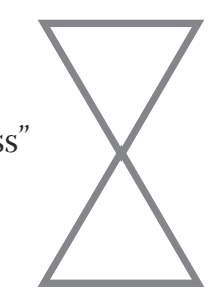
paragraphs it takes a turn and becomes a narrative, usually told in chronological order. Sticking with the example of the story about the massive storm, a reporter could start with a hard lead, provide a few paragraphs of support, and then tell the story of the storm as witnessed by one survivor. This kind of story form requires a clear transition between the opening section and the narrative. A reporter might write something like, "Farmer Iqbal Khan was in his barn when the wind kicked up ..." to begin the bottom half of an hourglass story. Some stories are written in a purely 
chronological form, but this structure is most often used for features.

\section{Diamond}

Still another story form is the "diamond" structure. A reporter using this structure would begin with an anecdote, introducing a character whose experience illustrates what the story is all about. This small story would then broaden out to show its wider significance. Toward the end, the reporter would return to the individual character's story as a way of concluding the narrative.

Reporters using this structure often use a device known as a "nut" paragraph (or nut graph) to explain why the story matters - the word "nut" signifying the hard center of the story. Jack Hart, managing editor of Portland's Oregonian newspaper, says nut graphs "can answer any questions raised in leads, explain why stories are significant, and place stories in meaningful contexts." The nut graph needs to be early enough in the story to make clear to the reader why he or she should bother to keep reading.

The diamond form is frequently used in television news and newspaper reports. For example, a reporter might begin a story about a new AIDS treatment by introducing a patient who needs the treatment, then describe the experimental drug and how it works, and conclude by noting that doctors give the patient we met earlier only a limited time to live if the new treatment is not effective. Whatever form you choose, the middle of the story should keep the audience engaged and interested. Good writing, a magazine editor once said, makes the reader want to find out what happens next.

\section{Endings}

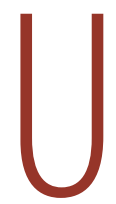
nless you are using the traditional inverted pyramid style and you expect the bottom of your story to be trimmed by an editor, it's a good idea to have an ending in mind when you begin writing, much as it is helpful to have a destination in mind when you set out on a journey. This is particularly important in broadcast news because of the way it's presented. Unlike print or online news, broadcast news is linear - the audience can't choose the order in which they'll receive the information - and research has found that viewers and listeners tend to remember best what they hear last. For that reason, many broadcast stories conclude with a summary ending, reinforcing the story's main point.

Endings often echo beginnings, in that they return to an important place or a person. In a chronological narrative, the ending is what happens last. If a story has raised a problem, the ending might offer a solution. Endings frequently look toward the future, to what might happen next. And occasionally a story may end with a strong quote or a sound bite. This is rarely justified, however, and should be used only when the quote is so powerful that writing anything more would be a letdown for the audience.

\section{Attribution}

A key difference between a news story and an editorial or opinion column is the use of attribution. Attribution simply answers the question, "Who says?" It identifies the source of the information reported, particularly any controversial statements or questionable information.

Attribution can be explicit or implied. Here's an example of explicit or direct attribution: "The man was arrested and charged with murder, police sergeant Antonio Costa said," Rewritten, using implied or indirect attribution, the sentence would read, "Police arrested the man and charged him with murder." In both cases, the audience can tell that the source of the information is the police.

One major reason to attribute information in most news stories is to allow readers, listeners, and viewers to decide for themselves whether to believe it. For example, a report that North Korea has decided to suspend its nuclear program could be seen as more or less credible by some audiences, depending on who 
is quoted as saying so: a visiting Chinese official or an international team of scientists.

Another reason for attribution is to place responsibility for a controversial statement where it belongs, with the person who said it, not with the reporter or the news organization. This does not imply immunity from lawsuits, as legal protections vary from country to country. But it is good journalistic practice to make clear who is making allegations or taking a particular stand.

Not all information in a news story needs to be attributed, however. Naming the source of every bit of information would make stories almost incomprehensible. Information that a reporter observed directly can be stated without attribution. Indisputable or wellaccepted facts do not need to be attributed, either. For example, a reporter could say which team won a soccer match without attribution because the final score would not be in doubt. But writing that one candidate won a political debate would need to be attributed, or it would cross the line from fact into opinion.

\section{Quotes and Sound Bites}

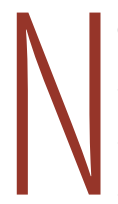

ews stories are told primarily in the reporter's words, but most stories also include the words of other people, in quotations or sound bites. When used effectively, quotes make stories stronger by sharing the direct experience of someone involved. Using a quote up high in a story can make it more interesting to the audience, because quotes provide a personal connection to the story.

By definition, a quotation must be attributed so the audience knows who said it. Direct quotes are at least one sentence long and are in the exact words of the speaker. They're used when most of what a speaker said is worth repeating. Partial quotes, primarily used in print, can be just a word or a phrase the speaker said, which are used when the full sentence may be confusing or too long. The reporter has the responsibility of putting partial quotes into context so the meaning of what the speaker said is unchanged. For example, when French President Jacques Chirac addressed his country after weeks of social unrest, he said: "We will build nothing lasting without fighting discrimination, which is a poison for society." Some reporters used that full, direct quote in their stories. But in London's Guardian newspaper, only one word of the quote appeared in the lead paragraph: "Jacques Chirac ... launched an appeal to combat the 'poison' of racial discrimination."

It's never worth quoting everything someone says in an interview. But how do you choose what to quote directly? The basic rule is simple: Don't use a direct quote or sound bite if you can say it better yourself. Too many news stories are stuffed full of quotes that fail this test, most of which come out of the mouths of officials. Avoid quotes that merely state facts, especially in bureaucratic language. Who needs to hear the mayor say, "We expect to have a decision next week on contingency plans for the distribution of municipal funds to lowincome recipients"? That kind of information would be much better paraphrased, that is, rewritten in clear, concise language by the reporter. In this case, the reporter might have written, "It will be at least a week before people can expect to get any money from the city, according to the mayor."

The best quotes are subjective, adding insight and perspective to stories. They use colorful language and reflect on personal experience or expert knowledge. They have passion, says television investigative reporter Tony Kovaleski. "During interviews, try and capture the passion," he says. "During writing, make sure not to miss it." One good rule of thumb is to use quotes that sound authentic, not as if they have been read from a script.

Once you've chosen the best quotes, build your story around them. But reporter Bob Dotson, with U.S. television network NBC, warns, "Don't use sound bites as substitutes for more effective story telling." Reporters who simply string quotes or sound bites together often are taking the lazy way out. 


\section{Numbers}

A journalism teacher once described her students as "do-gooders who hate math." Most journalists will never come to love mathematics, but they need it, and they need to know why. Numbers may look solid and factual, but they are not infallible. Journalists need numerical competence in order to tell the difference between a meaningless number and a significant one, or they risk writing stories that are misleading and confusing, at best, and, at worst, flat out wrong.

Journalists need mathematical intuition so they can tell when the numbers they're looking at just don't add up. They need math mechanics to find the meaning behind figures and data. They need mathematical concepts so they can understand banking and business, bankruptcy and boom times. Simply put, journalists need mathematics skills to make sense of numbers the way they need language skills to make sense of words.

Competent journalists are both capable and careful with numbers. They're quick to spot an implausible number, and they have a basic working knowledge of arithmetic and statistics so they can confirm their suspicions. They know how to calculate percentages, ratios, rates of change, and other relationships between numbers that tell far better stories than raw

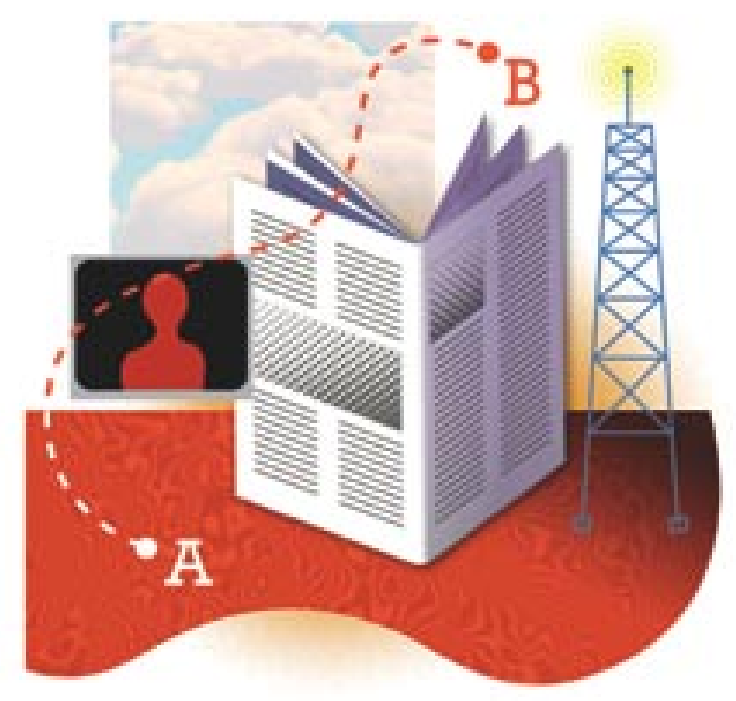

data can. They can and should translate numbers into terms that readers and viewers can easily understand.

Journalists with numerical competence are more important than ever in today's highly technical world. They are the writers and editors who can assess and explain scientific, medical, technological, and economic developments. They are the journalists who can find stories in databases by crunching numbers themselves, instead of waiting for someone with a vested interest to do it for them.

Once the numbers have been checked and rechecked, the reporter has to decide how to use them in a story. The rule of thumb is: The fewer numbers, the better. Numbers should be rounded off for simplicity's sake, and put in context for clarity. "A number has little significance on its own," says Paul Hemp, author of Ten Practical Tips for Business and Economic Reporting in Developing Economies. "Its true meaning comes from its relative value." So a story about an increase in school spending might translate the raw numbers into the additional amount that will be spent per child. A story about the number of people who die of lung cancer every year might note that it is the equivalent of a jumbo jet crashing every day.

Journalists who fail to master mathematics lack a basic skill needed to decipher much of the information in the world around them, such as crime statistics, pollution standards, and unemployment figures. Without mathematics skills appropriate to their beat, journalists are bound to fall short in their quest for accuracy. 
EDITING THE STORY

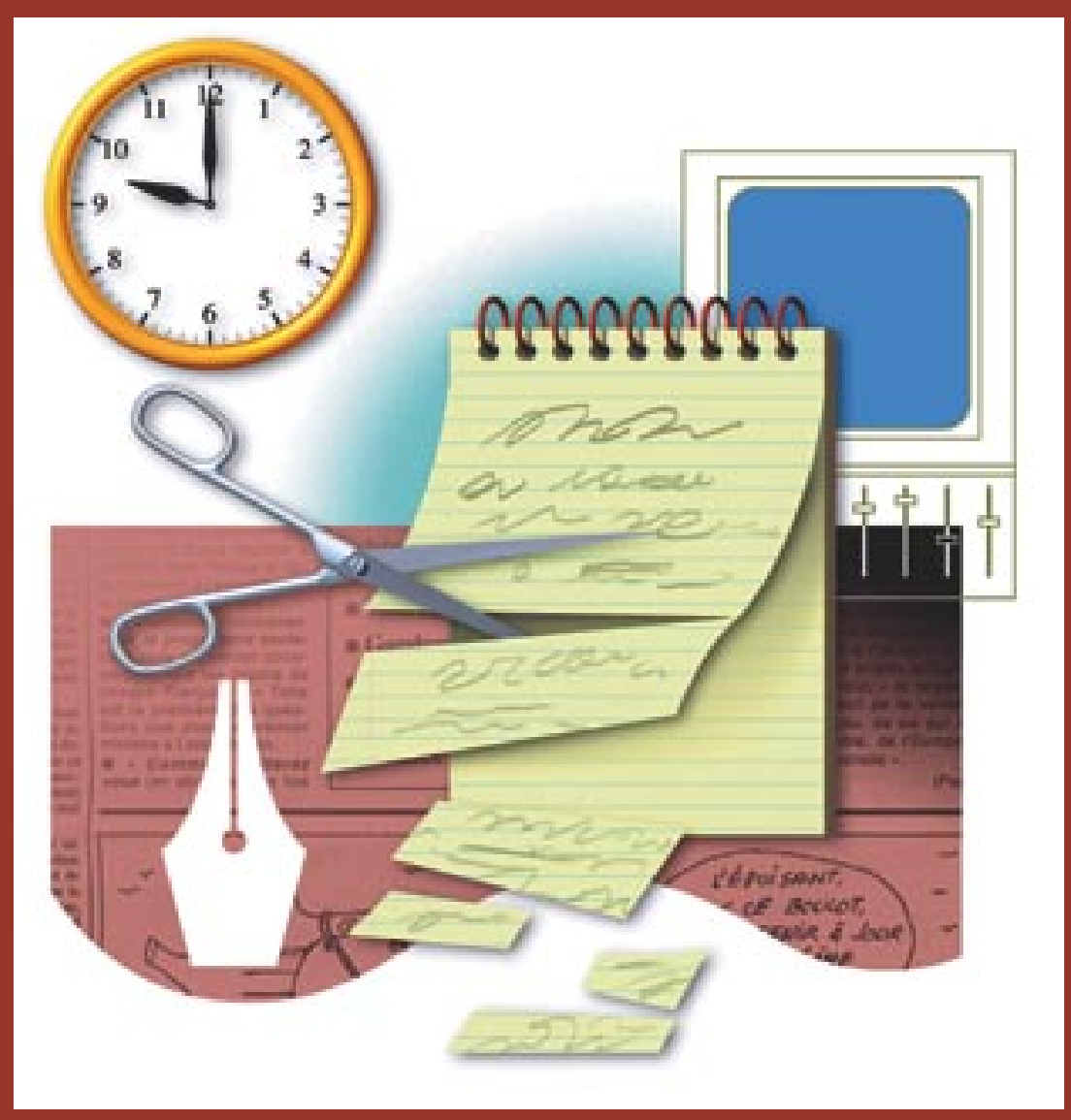




\section{It's nine $0^{\prime}$ clock in the morning, and the editorial meeting in}

\section{the newsroom begins with a discussion of the stories everyone}

is working on for that day. Some reporters and photographers already have assignments and are out covering today's news. A few got their assignments last night; others were sent out early

this morning after a conference call involving top news managers. Reporters who do not have assigned stories yet "pitch" their story ideas at the meeting, seeking a manager's approval to produce that story for tonight's newscast or tomorrow's newspaper. The assignment editor runs through a list of scheduled events that may or may not merit coverage. Once the decisions are made, the managers put together a "budget," or line-up of stories that they hope will soon be available for publication or broadcast.

At that point, you might think the managers could sit back and relax. But no decision in a newsroom is ever set in stone. Almost inevitably, plans change. News will happen that was not anticipated, and stories will be dropped because they didn't turn out as expected.

Others will require more reporting and won't be completed today. Deciding what to run, what to drop, and what to hold is the job of the news managers, the editors, and producers. They will choose and change the stories of the day based on importance, interest, new developments, and the time or space available.

But the editor's job still isn't done. Before the newspaper goes to press or the broadcast hits the air, editors have another critical role to play. It's their job to ensure that the stories presented to the public are well written and presented, as well as accurate, complete, and fair.

Most newsrooms have more than one editor. No single person could handle the volume of stories produced by most news organizations every day. In large newsrooms, there may be several layers of editors, who ultimately report to the person in charge of the news division, the chief newspaper editor or the broadcast news director. As you will see, the editor's job calls for a variety of skills, a high degree of literacy, as well as the ability to handle a changing agenda and work relentlessly under pressure.

\section{Newspaper Jobs}

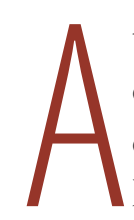
typical daily newspaper has a staff of reporters who cover a wide range of news. Most of the reporters at a local newspaper usually work for the "city" or "metro" desk, covering stories in the community the newspaper serves. A large newspaper with national circulation adds national and international or foreign desks, with reporters based in the nation's capital and in other countries. Some reporters work for specialized sections of the newspaper, covering sports, business, or features. Each of these desks or sections is headed by an editor, who oversees the reporters' work and who may be assisted by one or more sub-editors.

Newspaper editors assign the stories, they edit the written text or "copy," and they supervise the design and layout of pages. In most large newspapers, editors specialize in just one of these tasks, but at smaller newspapers, one person may handle them all. In addition, newspapers may have a photo editor who oversees a staff of photographers, as well as a graphics editor who supervises the work of artists creating maps, charts, and other informational graphics. Large newspapers also 
have a staff of researchers who help reporters find background on stories and who maintain a library, or "morgue," of stories published by the newspaper.

\section{Broadcast Jobs}

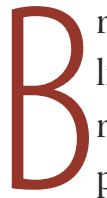

roadcast newsrooms are not organized like newspapers. Most broadcast reporters do not specialize in covering a particular type of story, but may instead be assigned to specific news broadcasts like the early morning news or the late night news. Each of these broadcasts is put together by a producer, who decides what stories will air, at what length, and in what order. In larger newsrooms, an executive producer supervises the work of the producers.

In addition to reporters, broadcast newsrooms have presenters or "anchors" who appear on the air and introduce the stories the reporters have covered that day. Radio and television anchors usually appear on more than one newscast per day.

The title of editor in a television newsroom sometimes is given to the person charged with the technical production of news stories, the one who cuts the video and sound together to make the finished product that goes on the air. In many newsrooms, the photojournalist who shot the video does the cutting, working with a script written and voiced by the reporter.

\section{The Editor's Role}

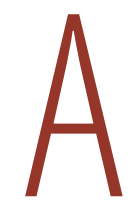
recent job listing for an editor at a small newspaper read, "This person should have strong writing, editing, and layout skills.... He or she should be accurate, responsible, able to work well within a team atmosphere, and possess supervisory skills." A large television station seeking to hire a new producer asked for "expert news judgment ... superior writing skills ... must have management skills, must be multi-task oriented, and well organized."

\section{Editors need to be} strong journalists

\section{and newsroom}

leaders.

As you can see, editors need to be strong journalists and newsroom leaders. They are involved in the news process from beginning to end. Editors need good news judgment because they serve as assignment managers, responsible for deciding what stories will be covered and by whom. They must be good writers in order to help to shape the story as it is developing, discussing it with reporters in the field and deciding where to deploy more people to cover additional angles. Editors are directly involved in decisions about story presentation, writing or choosing headlines, captions, photos, and illustrations. And they must lead and motivate the employees who report to them.

Editors and producers work closely with reporters, discussing and reviewing their stories. Newspaper editors check copy, choose illustrations - either graphics or photos - and decide how the story will be laid out on the page as well as the headline. In most broadcast newsrooms, reporters do not record their scripts or assemble their stories until a producer has approved the content. Producers also decide the order of stories in the newscast and the amount of time to be allocated to each story.

\section{Copy Editing}

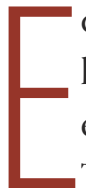

ditors serve as a second set of eyes looking for any errors in a story. The emphasis here is on a second set of eyes. That's because reporters should always check their own copy for accuracy before submitting it to an editor. A first draft is a good start, but that's all it is. Every writer should allow some time for revising his or her own copy. Good writing, by definition, requires rewriting. 
An accuracy check is the first level of copyediting. Editors look for grammatical and usage errors, as well as for spelling mistakes. They pay particular attention to subject-verb agreement and subject-pronoun agreement. Editors make sure that all numbers in a story are correct: addresses, telephone numbers, ages, date, and time references. They rework any calculations the reporter may have performed to make sure the math is correct. They confirm that the reporter has used proper titles for everyone who is quoted, and they review the use of attribution throughout the story.

Editors also look closely for any errors of fact or issues of fairness. Thorough editors read stories with a skeptical eye, with questions like these in mind:

- How does the reporter know this?

- Why should the audience believe this?

- Is the main point of the story supported?

- Are the quotes accurate, and do they capture what the person really meant?

- Are all sides represented?

- Is something missing?

- Is the story fair?

Editors also pay attention to matters of taste and language, which vary depending on the local culture. (We'll talk more about that in Chapter 7, "Ethics and Law.") Editors and reporters alike should read copy out loud especially in broadcast newsrooms - listening for sentences that are too long, redundancies, awkward phrases, and double meanings. In many newsrooms, editors have the authority to change a reporter's copy without consultation to fix these kinds of basic problems.

Editors are not simply proofreaders, however. They are journalists in every sense of the word. Most editors and producers either have reporting experience or reporting skills. So when they read a reporter's story, they are looking for much more than basic accuracy. They want to know if a story would make sense to someone who knows nothing about the subject. They're mindful of the need to make stories engaging and interesting.

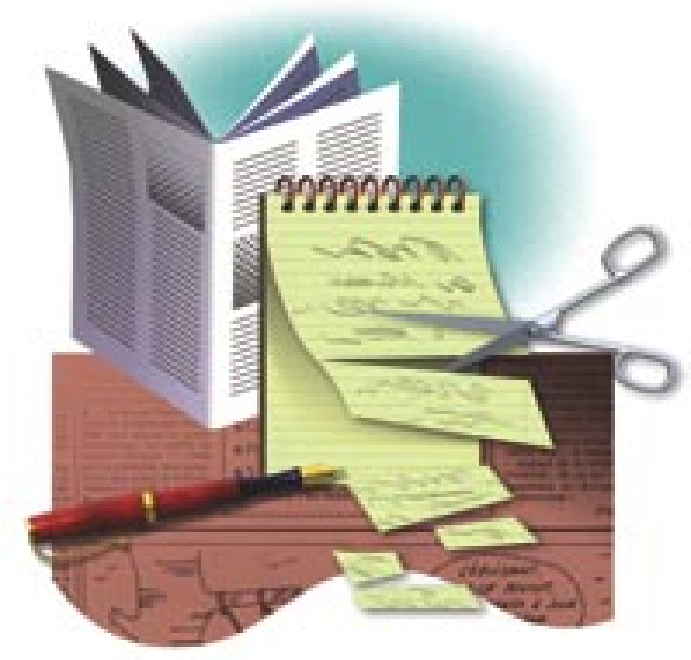

If a story falls short, the editor or producer must be able to work with the reporter to improve the final product. That's when their leadership skills come into play, as they use a process commonly called "coaching."

\section{Coaching}

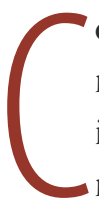

oaching is a way for editors to help reporters solve a story's problems independently. It avoids the resentment reporters often feel when an editor fixes problems by rewriting their stories. And it helps reporters learn how to do better work, rather than repeating the same mistakes and letting the editor step in and fix them. "A good editor coaches reporters through talking to them while they report and write," says Joyce Bazira, a news editor at the Tanzanian newspaper Alasiri. "Through coaching, writers can also ... discuss the problems they are encountering in doing their assignments, with the editor trying to solve them."

The skills involved in coaching are some of the same skills that distinguish a good journalist: listening attentively and asking good questions. Coaching works because reporters generally know the problems they are having with a story, even if they can't quite decide what to do about them. The job of the coach is to ask questions and listen, and help the reporter improve the work. That's quite different from the "fixer" role that some editors play: 


\section{$\mathrm{COACH}$}

Helps the writer;

Helps throughout the process;

Develops the writer;

Builds on strengths;

Fosters independence;

Shares control.

Many editors resist coaching reporters because they think it takes too much time. They believe it's faster to make the changes themselves. When the deadline looms, coaching may be impractical. The newspaper must be printed on time, the newscast must go on the air, and mistakes cannot be allowed to go through. But in newsrooms committed to coaching, editors don't wait until the last minute to check a reporter's copy. By working with reporters throughout the process, editors help reporters produce better stories that require less editing time at the end of the process.

Botswanan journalist Rodrick Mukumbira, currently with the Ngami Times, says he considers coaching a central part of his job as a news editor. "An editor should not only assign a reporter and correct mistakes in the final draft," Mukumbira says. "He should intervene in the reporting process - when the reporter is struggling with the lead - to save time on the final article."

A coaching editor will talk to reporters before they leave the newsroom, when they call in from the field, and as soon as they return, before they begin to write. The coaching editor asks simple questions that can help the reporter focus the story, such as:

- What happened?

- What is your story really about?

- What does the audience need to know?

- How can you make this clear?

- What do you think of your story so far?

- What needs work?

- What do you need to do next?

- How can I help you?
Editors who coach always look for something to praise and encourage in every story, and when they point out problems they focus on only a few at a time. The Poynter Institute's Jill Geisler says that when she coaches, she sits on her hands. As a coach, she does not want to touch the reporter's copy but rather to let the reporter talk about the story so she can listen for clarity and raise questions the writer needs to answer.

Coaching creates sharper journalism in a more humane newsroom. It makes dialogue a reward, not a punishment. And because people remember what they practice, coaching ultimately helps journalists do better work.

\section{Headlines, Captions, and Teases}

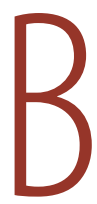
esides editing reporters' stories, editors are responsible for additional material that accompanies the stories. In newspapers and online newsrooms, editors write headlines for stories and captions for photos. A headline is both a summary and an advertisement. It gives the audience a quick idea of what the story is about, and tells readers why they should be interested in reading the entire piece. A caption is more of a label, telling readers what the photograph or graphic shows. In broadcast newsrooms, producers may write headlines and also what are called teases, short descriptions of stories designed to make listeners or viewers want to stay tuned to get the full report.

Headlines, by definition, are short and catchy. A print headline summarizes the story, gets the reader's attention, helps to organize the news on the printed page, and, through the use of different sizes of type, indicates the relative importance of each story. When writing a headline, the editor simply does not compress the lead paragraph into just a few words. Good editors try to capture the central point of the story in the headline, so they need to understand a story fully before trying to write a headline. The editor has to read the story from beginning to end, and look at the photographs and graphics that will accompany the story. If the main point 


\section{Headlines, by \\ definition, are \\ short and catchy.}

isn't obvious, the editor should consult with the reporter rather than guess and risk printing a headline that is misleading or wrong. Besides, a confused editor is one indication that the story probably needs more work.

The language in headlines should be simple and straightforward. Use proper names and present tense. It's generally acceptable not to use conjunctions - articles like "the" - and to drop linking verbs like "is" or "were." A story that tells how a woman and her boyfriend were arrested for a string of bank robberies might be headlined: "Bandit, Boyfriend Held in Robberies." But avoid what editors call "headlinese," verbs that appeal to headline writers just because they are short. Verbs like "probe," "eye," "nab," "vie," and "huddle" almost never are used in conversation, so they don't belong in headlines.

A headline should match the tone of the story. Hard news stories demand a straight summary, like this headline from The Zimbabwe Independent newspaper, "Smugglers Dent Zimbabwe's Gold Production.” The headline makes sure the reader knows exactly what the story is about. Feature headlines, on the other hand, may only hint at the story's content, since they are written primarily to pique the reader's curiosity. For example, Argentina's Buenos Aires Herald ran this headline over a review of a new recording: "Sassy Madonna Goes Back in Time."

Because headlines have to fit in a restricted amount of space, the newspaper editor creates headlines the way you would build a jigsaw puzzle. The copy editor for an American newspaper - the Newark Star-Ledger - Joel Pisetzner, says, "I put words together like assembling a kidnap note. Scramble, rescramble, mix and match." While it can be fun, editors say it's important to always keep the reader in mind. Avoid trite or overused expressions and be extremely careful with puns or double meanings. Headlines that try too hard to be funny, clever, or gripping often fail. Above all, headlines must be accurate and honest, not misleading. What is in the headline must be in the story. Nothing annoys a reader more than a story that doesn't deliver what the headline promised.

Much like a headline, a broadcast tease is designed to draw the viewer's attention to the rest of the story. Teases are subject to many of the same rules as headlines. Producers must watch the story and talk to the reporter before writing a tease. Trite and clever don't work in teases any more than they do in headlines. And teases should not over-promise or over-sell the content of the story that follows.

Unlike a newspaper headline, the broadcast tease is written in complete sentences. It stands alone, separated from the story by other news or advertising content. A tease usually does not summarize the story the way a headline would, since its goal is to make the viewer want to stay tuned in order to learn more. Instead, producers write teases that leave some questions unanswered, or they may create anticipation by promising to deliver a benefit to the viewer who keeps watching.

To illustrate the difference, consider the lead of this story from an American newspaper, the Los Angeles Times, reported from Amman, Jordan: "An Iraqi woman appeared on Jordanian state television Sunday and confessed to being the fourth member of an al-Qaida suicide bomber team that attacked three hotels here last week, killing 57 people." The newspaper headlined the story: "Iraqi Woman Calmly Confesses How She Tried to Blow Up Hotel." But the tease for that same story on the NBC Nightly News on television was this: "Who is she? And why did she agree to be the fourth would-be hotel suicide bomber in Jordan? New details tonight." The television tease did not mention the woman's confession, but instead promised to answer the viewer's questions about her role. 
Photo captions also have a different purpose from headlines. Instead of summarizing content the way a headline does, a caption helps the reader appreciate what's inside the visual frame. The photograph and caption together form a small story that the reader can understand without having to read the text of the story that accompanies it.

Captions should clearly identify the main people in a photograph. If several people are featured, it's often helpful to let the reader know that the central character is the one "wearing a cap" or "standing on the right." Captions should not repeat the exact wording of the headline or lift a sentence directly from the story. And caption writers don't need to spell out what can be seen clearly in the photo. "Carlos Fernández smiles as he gets off the plane" is a less effective caption than: "A jubilant Carlos Fernández returns from 15 years in exile."

Most captions are short, just one or two lines in small type. But on occasion, a newspaper or online site will carry multiple photographs with longer captions in a photo essay that tells a complete story. Longer captions can use quotations from the people pictured.

\section{Graphics and Visuals}

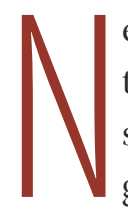
ewspaper reporters sometimes resent the use of graphics because they take up space, forcing stories to be shorter. But good graphics add to the visual appeal of the newspaper, attract readers' attention, and make stories more understandable. They help reporters' stories, rather than take away from them. As newspaper designer Ron Reason puts it, graphics are "information, not decoration."
Every graphic must have a purpose. Filling empty space or airtime is not a sufficient reason for using a graphic. A graphic should enhance the reader or viewer's understanding of the story, which means the editor must fully understand the story before designing or choosing a graphic to go along with it. Graphic artists usually produce the visual images; the role of the editor is to conceptualize the graphic, find the information it should contain or illustrate, and ascertain its accuracy.

Graphics can convey basic facts or illustrate a process. Imagine you are reporting on air pollution in your country. A map could be used to show where the air is most unhealthy. An illustration could be used to show how air pollution affects the lungs. Both types of graphics work just as well for broadcast as they do for print.

Whatever the medium, avoid graphics that are crammed with too much information. The reader or viewer should be able to look at the graphic and take away one basic idea. Think of a graphic as a highway sign - the driver doesn't get a chance to study it because things are going by too fast, so the information has to be clear and easily absorbed.

Let's imagine you have a story that says the city's annual budget is twice as large as it was 10 years ago. Reading closely, you notice that most of the growth has been in the last three years. A bar graph charting the size of the budget for each of the last 10 years would be an easy way to make that clear.

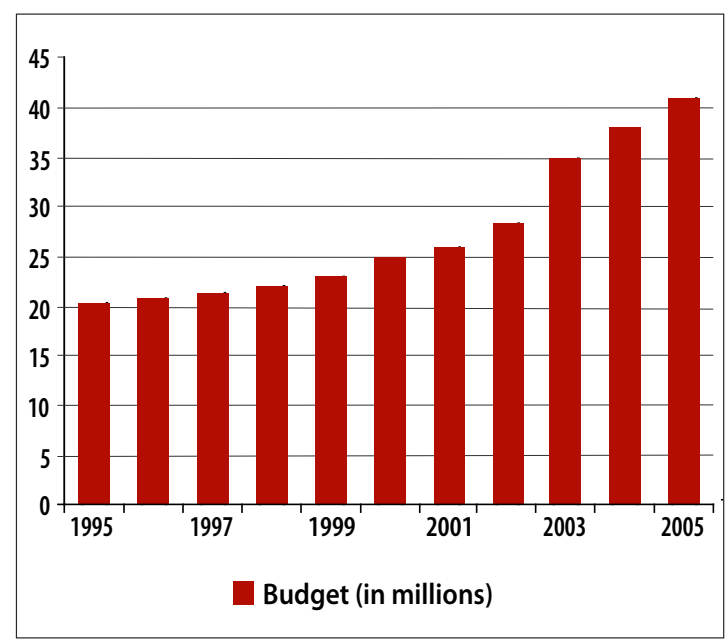


It is easier for readers and viewers to absorb information presented with shapes rather than raw numbers. For example, in a story about your city's business development crowding out residents, you could list the number of apartments and office buildings in the area. However, it would be more effective to create a pie chart showing the relationship between the two. Compare rates whenever possible, not raw numbers. It is misleading to show that one town has twice as many deaths from AIDS as another, when the first town has 10 times as many inhabitants. Calculate the rate of deaths per inhabitant so you can make a fair comparison. Editors who work with graphics need a grasp of statistics and a commitment to employ them transparently and accurately to enhance understanding.

\section{Supervising}

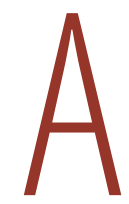
S we've already noted, editors are supervisors as well as journalists. As they work with reporters on daily stories, they also oversee their progress over the long term. They look for opportunities - either in person or on paper - to provide constructive feedback that will help reporters improve their work. Many editors also are responsible for annual performance reviews of the employees they supervise, which is a more formal type of feedback.

Effective feedback is timely and specific. It is provided both in person and in writing. And most editors believe in providing some positive feedback in public but keeping all critical comments private. For most busy editors, the only way to ensure that their employees get the one-on-one feedback they deserve is to schedule regular feedback sessions. Letting employees know how they are doing on a routine basis is a good way to avoid unpleasant surprises at performance-review time.

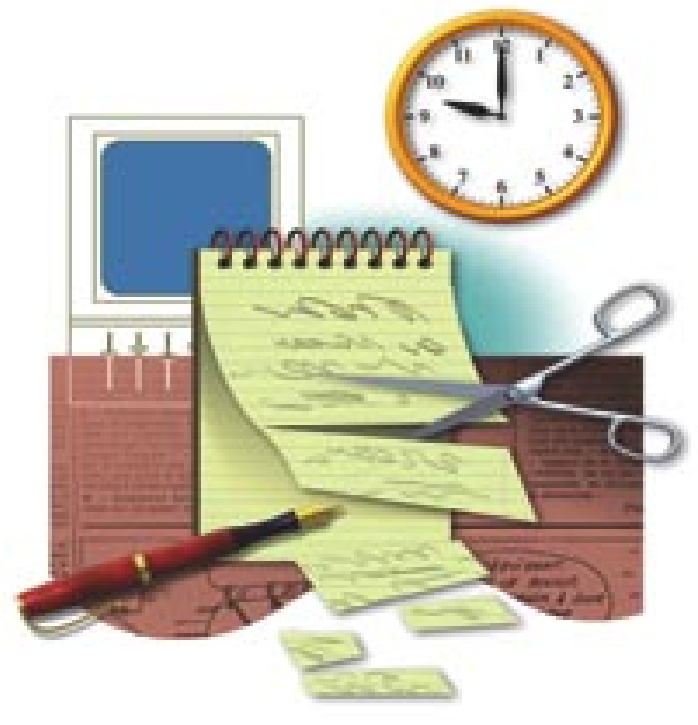

News managers should find a way to get honest feedback from the staff on their own performance. This can be done through informal conversations or by asking employees to fill out an anonymous questionnaire. Either way, it's important for managers to stress that they want people to be candid, and to avoid bearing grudges if the results are not entirely favorable. The point is for them to learn how they're doing so they can improve their own performance.

Top editors and news directors set the tone for the newsroom and help to create a positive newsroom culture, establishing and reinforcing the norms and values that employees share. In a well-managed newsroom, editors avoid playing favorites. They encourage open communication and hold regular meetings to make sure everyone understands the goals of the news organization. Editors should pay close attention to staff morale, and do what they can to bolster it by celebrating successes and rewarding outstanding achievement. Recognizing good work in a public setting is one way to get more of it. 


\section{BROADCAST AND ONLINE}

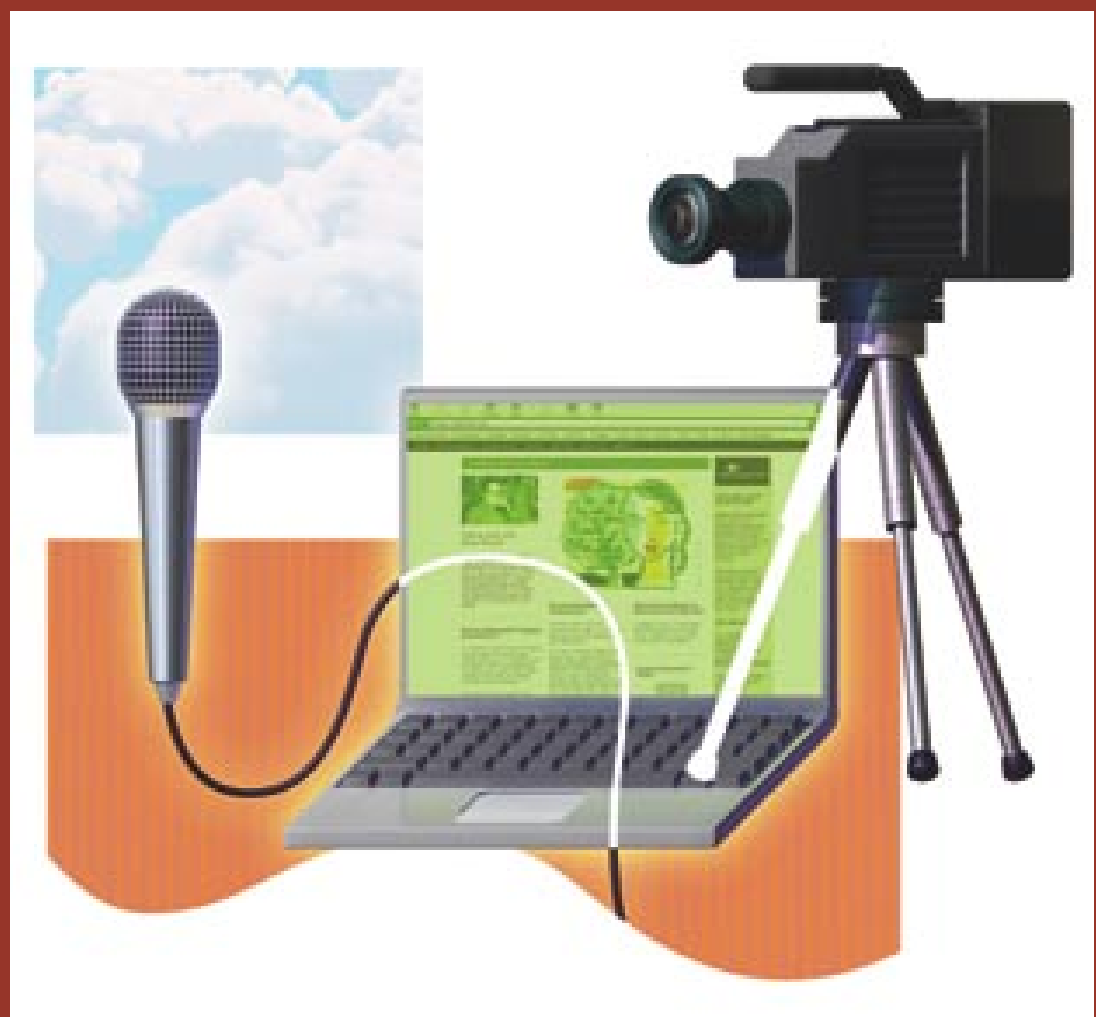



above those we have discussed so far. Broadcast journalists use not only words, but also sound and video in constructing their stories. What they write must be written to be heard, not read,

by the audience. Like their TV counterparts, online journalists can include sound and video in their stories, as well as interactive elements that allow a reader to explore the story at his or her own pace.

For simplicity's sake, we'll use the term broadcast in this chapter to describe all radio and television news, whether it's transmitted over the air, on cable, or via satellite.

\section{Broadcast Story Forms and Terms}

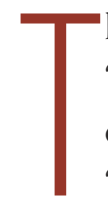

he basic broadcast story forms are the "tell" or "reader" story, the "V/O" or voice over, and the "wrap" or "package." A "reader" story is just what it appears to be - a story without additional sound bites or video - usually presented by the newscaster or anchor in the studio. A "V/O" is a television term for a story told with video but no "sound bites," the broadcast term in English for direct quotes. The newsreader or anchor will read the script for the story while the video is playing. Adding a sound bite turns a V/O into a "V/ O-SOT," shorthand for sound on tape. Even though many stations now capture all video digitally without using tape, the abbreviation SOT appears to have stuck. These story forms - reader, $\mathrm{V} / \mathrm{O}$, and V/O-SOT - tend to be short: usually less than a minute, and sometimes only 10 or 15 seconds long.
A complete story by a reporter is called a "wrap" in radio and a "package" in television news parlance. It consists of the reporter's narration, also called “track," and often includes sound bites and natural sound, sound that occurs naturally on location. Obviously, the television version has video, which may include graphics, either static or animated. These types of stories can be presented live or recorded in advance, and they tend to run longer than the other story forms - sometimes up to six or seven minutes, depending on the format of the newscast. Each package also has a "lead-in," or introduction, to be read by the newscaster. Many also include a "tag," which provides additional information at the end of the reporter's package.

Another type of broadcast story is known as a "natural sound" or "NATSOT" package. This story form is most often used in television but occasionally in radio as well. It does not include any reporter track. Instead, the people featured in the story have to provide the narration. This approach can require more planning and just as much reporting as any other story, but the results can be powerful. Photojournalists, who sometimes produce this type of story on their own without a reporter, have to make sure that every bit of information needed to tell the story is captured on tape or else the final product won't make sense. 
Radio and

\section{television stories}

\section{are written for the listener's ear.}

\section{Broadcast Writing}

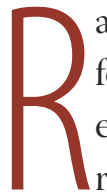
adio and television stories are written for the listener's ear, not the reader's eye. Reporters must write copy they can read out loud: clear, conversational copy that is easily understood. Unlike newspaper or online readers, the broadcast audience can't go back and take a second look or listen to a story that didn't quite make sense the first time. "The words are spoken and, once spoken, are irretrievable," former CBS (U.S. TV network) News editor Ed Bliss once wrote.

Broadcast journalists are more concise than their newspaper colleagues. They have to be. The printout of a half-hour news broadcast would fill only a page or two in the newspaper. A broadcast lead cannot include all $5 \mathrm{Ws}$ and the $\mathrm{H}$ discussed in Chapter 2 - it would be too long and too hard to follow. Instead, a broadcast writer will select the two or three most significant points to use in the lead, and put the rest in the sentence that follows. Broadcast stories also tend to leave out some details, such as ages and addresses, which are routinely found in print. Broadcasters write shorter sentences so they can read them aloud without running out of breath.
Reporters for radio and television must be attuned to the sound of the words they use. Like poets, they are alert to pacing and rhythm. Consider this sentence from a script by Edward R. Murrow, the famed CBS correspondent who covered World War II from London, "The blackout stretches from Birmingham to Bethlehem, but tonight, over Britain, the skies are clear." This is writing that is meant to be heard. The words are simple; the ending is crisp.

Broadcast writers must be wary of language that might be correct on the printed page, but sounds ridiculous when read aloud. When the American actress and TV entertainer Lucille Ball died, a print story called her "the 83-year-old Ball." On the radio, the story said, "Lucille Ball was 83 years old." (It thus avoided confusion over other meanings for "ball" in English.) Broadcast writers also should beware of words that sound alike but have different meanings. In English, for example, "miner" could easily be confused with "minor." These words must be used in the proper context so their meaning is clear. Broadcast journalists make a habit of reading their copy out loud before going on the air to catch this kind of problem, as well as potentially embarrassing double meanings that are not obvious on paper. Reporting on a charity golf tournament, you don't want to say that someone "played a round with the prime minister." ("Play around" in English can connote "misbehaved with.")

Even though broadcast scripts are written to be read out loud, it's just as important to spell correctly for broadcast as well as print. Misspellings often result in stumbles or mispronunciations on the air. To make sure they know how to correctly pronounce difficult words, broadcast journalists often include phonetic spellings in their scripts. Correct spelling also matters more today because many stations post their stories online. Some stations have computer software that automatically converts scripts into closed captioning or subtitling for their newscasts as a service to deaf viewers. In both cases, misspellings reflect badly on the reporters and the station. 
Radio and television news is written in a more conversational style than news in print. Put another way, broadcast journalists should write the way they speak. A newspaper story might read, "The man escaped in a red Toyota truck, police said." But in broadcast, attribution comes first, so the script would read, "Police say the man escaped in a red Toyota truck." To maintain a conversational tone, broadcasters don't need to use complete names and titles in news stories. Generally speaking, middle initials are not used on the air unless the initial is an essential part of the name. And at times, not even the name is required. A newspaper story would note, "Pakistani Foreign Minister Khurshid Mahmood Kasuri met his Israeli counterpart Silvan Shalom in Istanbul, Turkey, on Thursday." But the radio story might simply say, "The foreign ministers of Pakistan and Israel met in Turkey today."

Immediacy is a key feature of broadcast news. If something is happening while you are on the air, you can and should say so: "The president is flying to Capetown ..." is more immediate than, "The president flies to Capetown today." Generally speaking, radio and television reporters avoid using time references in their leads unless the event happened today. Where Wednesday's

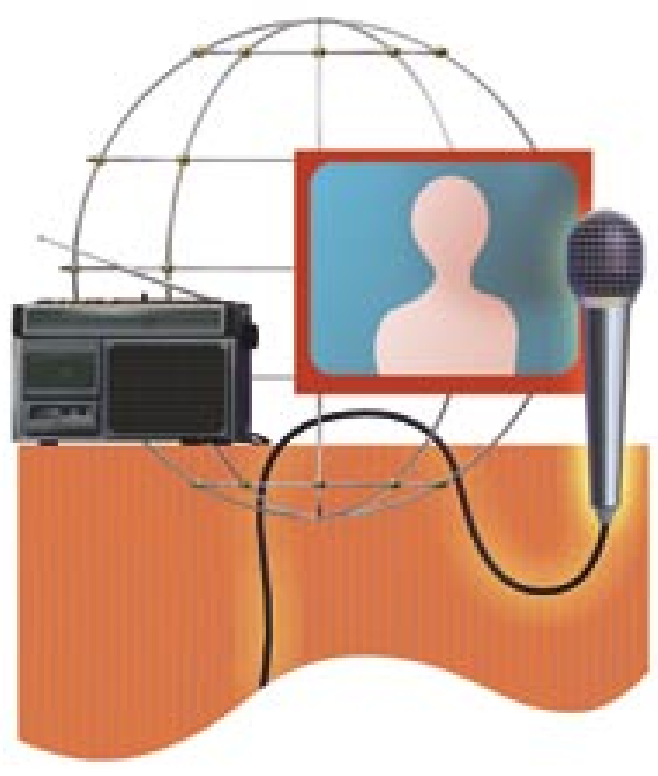

newspaper would publish this lead: "President Mbeki flew to Capetown on Tuesday," the radio newscast Wednesday morning would put it differently: "President Mbeki has arrived in Capetown." Better yet, the writer would look forward to what the president is doing in Capetown on Wednesday so the story could be written in the present tense: "This morning, President Mbeki meets with students at the University of Capetown."

\section{Sound}

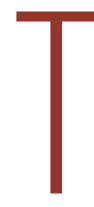

he sound bites that radio and television reporters use in their stories are the broadcast equivalent of quotes, but choosing them requires an additional layer of decision-making. It is not enough for the sound bite to make sense on paper. It must be clear enough to understand over the radio or on television. Broadcast journalists have to be mindful of how long a sound bite runs. What looks short on paper may actually take someone quite a long time to say - so long, in some cases, that it cannot be used in its entirety without making the entire story exceed its allotted time.

Broadcast writers pay particular attention to the transitions into and out of sound bites. Their goal is to create a seamless narrative that will retain the attention of the audience all the way through the story. If a sound bite begins with a pronoun, for example, the writer must make the meaning clear at the front end, by crafting the sentence so that the ear gets the information needed to decode what's coming next. Let's say there's an outbreak of head lice in the local schools. A school nurse says in a sound bite, "They come in here scratching and we just know what we've got. It's so obvious." When she says "they," she means the schoolchildren. It won't do if the sentence before that sound bite says, "School nurses say they are dealing with a terrible outbreak of head lice," because the sound bite that follows would appear to suggest that "they" refers to head lice. 
Instead, the reporter might say, "The outbreak of head lice means that nurses like Mary Smith are seeing a lot more children than usual today."

In addition to sound bites, stories on radio and television may include so-called "natural" or "wild" sound. This is sound that is captured while reporting a story: the whistling of the wind, a police siren, children shouting for joy. Using this sound in telling the story is standard practice in some parts of the world. Including natural sound allows listeners or viewers to experience a place or situation for themselves, instead of the reporter telling them about it. Sound also can provide an audio transition from one location to another, leading the audience into the next scene.

Natural sound can be used at a low audio level, under the reporter's words, or "up full" so it can be clearly heard. Either way, the sound helps the reporter tell the story. Like mortar between bricks, good natural sound holds the story together. American photojournalist Steve Sweitzer says that, in television, using natural sound is essential to tell a complete story. "Sound is the other part of the picture," he says.

\section{Broadcast}

journalists should

$$
\text { write the way }
$$

$$
\text { they speak. }
$$

\section{Pictures}

T elevision is much more than radio with pictures. Skilled television journalists marry their words with the video in order to tell a more powerful story. Pictures are not just video "wallpaper," they are an essential part of the story. The visuals tell the "what" of the story. The words tell the "why." To quote Ed Bliss again, "Seeing may be believing, but it isn't understanding."

Television reporters need to know what video they will use in a story before beginning to write. Whenever possible, they should look at all of the video first, so they can be sure that what they write will match the pictures. This is not just an issue of style. Research has shown that viewers understand and remember stories much better when the words and video match, that is, when they tell the same basic story. When the video does not match the words, viewers tend to remember more of what they see than what they hear. Imagine, for example, a story about the effects of a major storm on a country's fuel supplies. If the video shows only storm damage and its aftermath, the viewer might miss the central point that fuel supplies have been disrupted. The story would be easier to follow if the video showed storm damage while the reporter talked about the aftermath, and then switched to pictures of stranded fuel trucks or people waiting in line trying to buy gasoline while the reporter described the effect of the storm on fuel supplies.

Synchronizing words and pictures does not mean that reporters should simply describe what the viewer can see. Let's say the video shows a farm truck driving down a dusty dirt road. There's no point in having a reporter say something obvious, such as, "The Robertsons live at the end of a long country road." Instead, the audio track should offer information that adds context and meaning to the picture. In this case, the reporter might say, "The drought has been so bad that the Robertsons haven't had any crops to sell this year." 


\section{Newscasts}

R eaders of newspapers or of news sites on the Internet have considerable control over how they receive the news. Radio listeners and television viewers have less. A newspaper reader can choose to begin with the front page, the sports section, or the obituaries. An online reader can scroll through a Web site's home page offerings before deciding what specific item to read from start to finish. But a radio listener or a television viewer has to consume the news the way it's made available; the order of stories is predetermined by the newscast producer.

Newscasts generally begin, or "lead," with what the producer believes is the major story of the day. That does not mean that every story following the lead is considered slightly less important than the one before it. The producer has to consider the impact of the newscast as a whole, not just each individual story. Producers often place an important or unusual story lower down in the newscast and "tease" what's coming next as a way of holding the viewers' interest and keeping them tuned in. (We talked about teases in Chapter 4.)

Much as a newspaper editor decides on the layout of pages, the television news producer creates a rundown or lineup for the newscast, listing all stories in the order they will run. The producer's job is to know exactly how long each story will last because the newscast must begin and end at a specific time. Once the program starts, the producer makes sure it stays on schedule. If a story runs longer than expected, the producer has to decide what to cut to make up for it. If a story is dropped, the producer has to provide material to fill the gap.

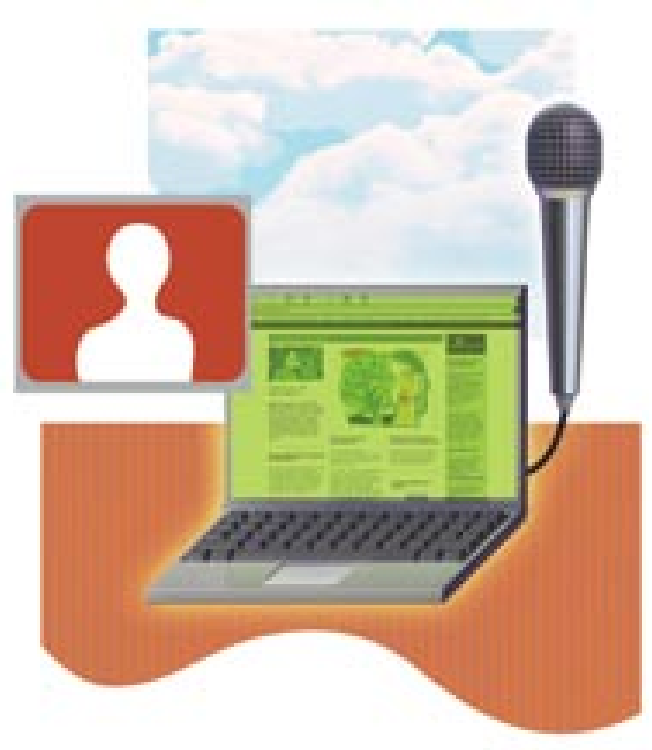

\section{Online News}

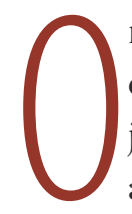
nline journalism has certain attributes of print journalism and of broadcast journalism, and other attributes that are unique to the Web. Frequently Web sites offer news articles to be read, just as they would be in a newspaper. At other times, the audience may select a video clip, so the Web site resembles a TV broadcast. An online story that takes full advantage of the new medium allows the reader to become a participant, choosing his or her own path through the information presented. "Only if there is some element of control by the user is it a new story form," says Nora Paul, director of the University of Minnesota's Institute for New Media Studies.

"Online journalists must think on multiple levels at once: words, ideas, story structure, design, interactives, audio, video, photos, news judgment," says Jonathan Dube, publisher of CyberJournalist.net, a Web site that focuses on how the Internet and other technologies are changing the media. "TV is about showing the news. Print is more about telling and explaining. Online is about showing, telling, demonstrating, and interacting." To make that possible, online journalists present information in layers, using a variety of story forms. 


\section{Online Story Forms}

T

he most basic online-story form has been described as "print plus." It's a text story that includes additional elements like photographs, audio, and video, or hyperlinks to more information. By embedding links, the journalist can take the reader to additional information on separate Web pages, some of which may be provided by sources outside the news organization, with more background or history. Online stories can be enhanced by including links to databases that a user can search. For example, a story about falling test scores at secondary schools across the country could link to a database of results from all schools. The user could search for a specific school, for all schools in a particular city, or compare the results of different schools.

A more innovative approach uses "clickable interactives" or multimedia graphics specifically designed to illustrate a story. The graphic elements are laid out in linear fashion, but the reader can explore them independently in any order. The same is true of most online "slideshows," which combine text and audio with still photographs in a multi-media experience for the user.

Tools that allow the reader to navigate through a 360-degree view of a location can enhance online storytelling, too. So can Flash animation, one of the software programs that allows you to design interactive content: video, graphics, and animation. For example, the BBC in London created a Web site about illegal drugs and alcohol that allowed the reader to "choose" a particular drug and dosage, and then select a part of the body - like the brain or heart - to read about the effects of that drug on that organ, as well as safety information. Online sites even have used quizzes and games to tell stories by breaking the information into questions and answers and letting the user discover what the reporter has already learned.

\section{Online Writing}

0 nline writing, says Jonathan Dube, is a cross between print and broadcast writing. He maintains that the short, simple style favored by broadcasters makes online writing easier to follow. But he says too many Web sites ignore the basic rules of good writing. A conversational tone is good, says Dube, but grammar and spelling still matter. Television news manager Scott Atkinson says his best advice is to write for the Internet as you would write an e-mail to a friend. "That doesn't mean you can misspell words, ignore story structure, or leave out context," he says. "What it does mean is you should write in the most intimate style you can muster."

Because Web-based news sites tend to offer readers many choices, writers should avoid delayed or anecdotal leads that don't quickly indicate what a story is about. The lead should give the reader a good reason to continue reading; otherwise, he or she probably will click on another story. Stories on line generally are shorter than newspaper stories. A good guideline is to limit an online story to about 800 words and to keep it all on one page. Studies have found that readers are willing to scroll through text on line; there is no need to force them to click to additional pages for more of the same story. But to make the text easier to absorb, Dube suggests that online writers break the text into more blocks and use more subheads and bullet points to separate ideas than they would in print. 
Online journalism may allow readers to respond immediately and directly to the writer or editor via e-mail or even in a live Web chat. In addition, many sites provide space for readers to post their feedback or opinions, so others can read what they have written and respond. Minnesota Public Radio (MPR) in the United States solicits input for stories both on the air and on line. Listeners are asked to call or e-mail additional information. Stories on the MPR Web site include a "Help us cover this story" link, so the audience can add comments and insights.

MPR also surveys its audience before producing special reports, such as an examination of the state's economy. MPR News Vice President Bill Buzenberg says audience input results in "much more sophisticated reporting, with more depth and lots of realworld examples and voices." 
SPECIALIZED JOURNALISM

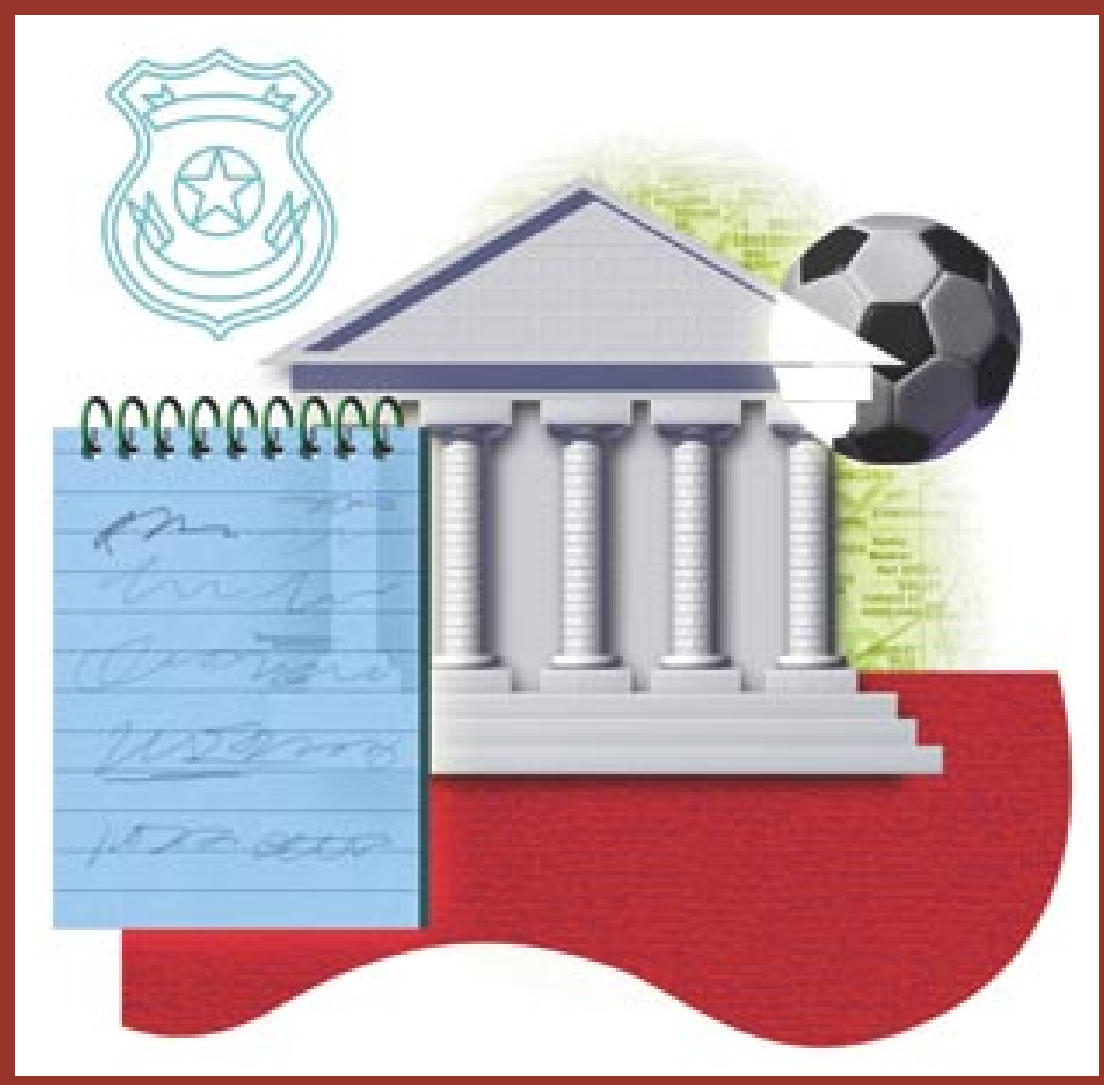




\section{Many news organizations assign journalists to cover specific}

areas, either geographic or topical, known as "beats." This is a term originally used to describe a regular route for a sentry or policeman. Journalists get to know the territory and people who make up their beat, and in many cases they have to learn

specialized vocabulary in order to understand their sources. This does not mean they use that vocabulary in their stories. On the contrary, good beat reporters become translators and interpreters, making information that might otherwise be obscure accessible to the general public.

Beats are rare in the smallest newsrooms, where every reporter is expected to cover every kind of story. But in larger news organizations, print and broadcast, journalists may have the opportunity to focus on a particular type of news. Some beats are traditional: government, police, courts, and business, for example. Others vary with the territory. Depending on a community's make-up, reporters might be assigned to cover the environment, or the elderly, or education as a beat.

Beat reporters have one basic responsibility: to stay on top of the news in their specialty area. They are expected to cover stories that arise on their beat - meetings, printed reports or Web postings, and other routine events - but they're also responsible for finding news that goes beyond the obvious. Beat reporters develop stories through their own enterprise, by building relationships with sources who will keep them abreast of what's really going on, not just in public but behind the scenes. They produce a wide variety of stories, from breaking news to feature profiles. "The best beat reporters I've known are well organized, determined, with a clear sense of mission, and a wide range of sources," says Chip Scanlan, a former beat reporter for Knight Ridder newspapers and currently with The Poynter Institute.

\section{Beat Reporting Skills}

W hatever beat a journalist chooses or is assigned to cover, one basic skill is essential: the ability to understand the institutions that dominate the beat. Learning how the system works takes time and effort, but it pays off in stories that non-beat reporters can't match. Eric Nalder, the reporter who uncovered the life raft story discussed in Chapter 2, uses these questions to begin learning his way around a beat:

- Who are the players?

- Who is in charge?

- Who are the regulators?

- What are the rules?

- How are things done?

- Where are the mistakes recorded?

- Where is the spending recorded?

- Who knows the real story and how can I get it?

To get answers to these questions, a reporter has to study hard and "walk the beat." Read everything you can about the topic, collect meeting schedules and agendas, subscribe to specialized publications. But most importantly, 
A reporter has to

\section{study hard and \\ "walk the beat."}

get up and go. Beat reporters cannot depend solely on the telephone; they have to spend time on the beat, meeting and talking with people.

"No one ever got a story sitting around the newsroom," says veteran American journalist Mike Mather, an investigative reporter at WTKR-TV in Norfolk, Virginia. Get to know everyone who could be helpful - from officials to clerks - and pass out your business card to everyone you meet on the beat. Build a source list with as much contact information as you can pry loose, and stay in touch with those people by making regular "beat checks." In addition to covering the key players on the beat, a good beat reporter also looks at how their actions affect people in the community.

Beat reporting requires strong organizational and personal skills. Staying organized means using a calendar to track meetings, hearings, and due dates for reports or action. It means having a reliable, portable system for filing and retrieving contact information, especially phone numbers and e-mail addresses. And it means keeping a file of future story ideas, with daily lists of things to follow up on. Many reporters now keep this information in their computers, using programs that make it easy to search for people and dates. But they also need it when they're not in the office, so they either carry a printout, a laptop computer, or that useful hand-held device that allows remote Web access, the personal digital assistant (PDA). Since technology can be unreliable, it's important to make a back-up copy of the information frequently.
Covering a beat means getting to know people well enough that they will trust you, while still maintaining a professional distance. The hardest part of being a beat reporter, says Scanlan, is "dealing with sources you have to return to every day even if you've written a story they don't like."

\section{Government and Politics}

R eporters who cover government need to understand its inner workings, and to look for the impact of government decisions. Reporters who ask the basic question, "Who cares?", when covering government are able to find people whose lives are affected by what government does. Stories that feature these people are more interesting to the audience.

Much of the business of government is conducted in meetings, so reporters on the beat should expect to cover plenty of them. A dull meeting does not justify a dull story, however. The audience depends on the journalist to tell them only what's important, not everything that happened in chronological order. The best stories about meetings focus not on what happened in the room, but on the people who are affected by what happened.

On the government beat, it's critical for journalists to know how to read and interpret a budget and other financial statements. "Follow the money" is good advice for all journalists, but particularly for those covering government and politics. Stories about government funding may seem dry, but taxes and spending affect the audience directly and people need to know where their money is going. In general, documents are the lifeblood of government, so beat reporters must be able to obtain them and understand them. 
Political reporters in a democracy have one central mission: to provide citizens with the information they need to make an informed choice between the candidates for elective office. To do that, journalists need to examine the candidates' backgrounds and qualifications, their positions on the key issues, and what the candidates are saying in campaign appearances and advertising. Reporters who cover politics look at the candidates' supporters, too, since their interests can often shed light on what a politician will do if elected.

Public opinion surveys are a staple of campaign coverage, but journalists need to look closely before deciding whether a poll's results are worth reporting (See sidebar, "Questions Journalists Should Ask About Polls," on page 53). "Horse-race" or "tracking" polls that tell the percentage of voters who support each candidate are of limited value except as a fleeting snapshot of the race on any given day. Some journalists believe these polls may actually bias voters in favor of the leading candidate because people generally want to support a winner. But researchers in the United States have discovered that voters who pay attention to polls also learn more

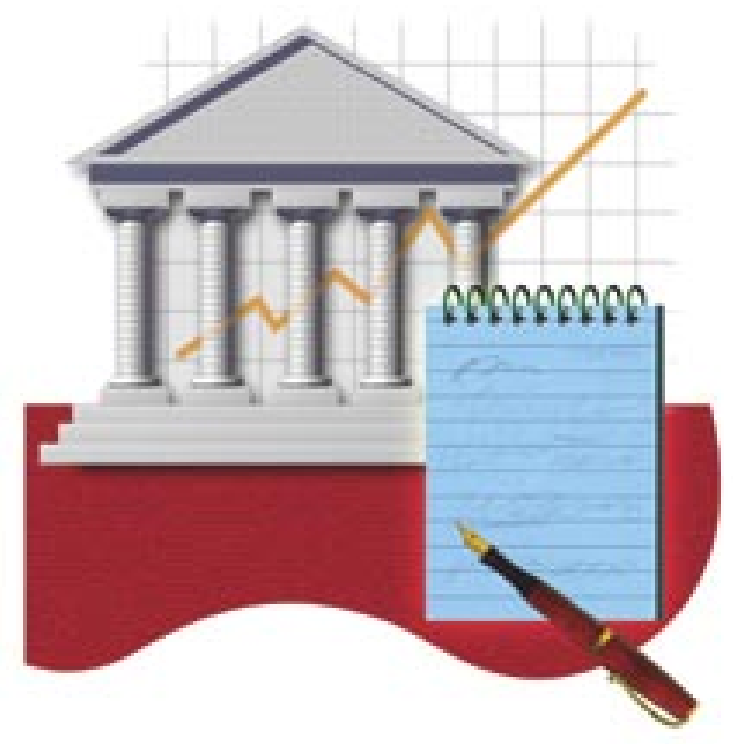

about the issues involved in the campaign. The researchers' advice to journalists is to keep reporting the results of legitimate "tracking" polls throughout the campaign, but not to make them a major focus of the coverage.

When it comes to campaign issues, journalists should pay attention not only to what the candidates say but also to what the voters want to know. Many news organizations conduct "issue polls" to see what topics are of great interest to the public during an election year. Sometimes candidates may try to avoid discussing a controversial issue that matters deeply to voters. In that case, journalists should raise the questions the public is asking. Good political reporters do not simply point out where the candidates stand on the issues, they ask what the candidates have done about those issues in previous elected office or in other positions they may have held. To bring the issues to life, reporters look for people whose individual stories illustrate why the issues matter and what difference it would make if one candidate or the other wins the election.

\section{Business and Economics}

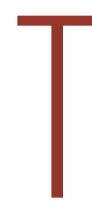

he business beat touches the lives of almost everyone. Unemployment, the cost of food and fuel, personal savings and investment, all of these topics matter not just to business leaders but also to workers and consumers. Covering the local business beat means reporting on employers and workers, construction, and property sales, as well as the business sectors that keep the local economy going, be it farming, manufacturing, mining, or health care. At the national level, business reporters cover more abstruse topics, such as commodity and stock markets, interest rates, and institutional debt. 
Reporters covering business and economics have to make their stories accessible to a general audience. They must understand economic concepts and terms and be able to define or restate them in plain language. This is good practice even for reporters working for specialized publications or broadcasts, whose audience might be expected to be familiar with the terms. In the United States, for example, The Wall Street Journal is aimed at businesssavvy readers, but still it spells out the meaning of common terms like "gross national product," the total value of a nation's output of goods and services. Over time, business reporters develop their own list of concise definitions they can plug into their stories. The audience will appreciate a clear statement of what is meant by "debt conversion," "currency devaluation," "privatization," and other economic terms. They will appreciate stories that explain why those concepts matter to individuals as well as to corporations and governments.

Business reporters need to be able to read and understand financial statements, balance sheets, and annual reports. They often find stories by looking at changes in income or spending from year to year. They compare companies to others in the same industry or the same region. For example, when a business closes or fails, reporters will ask not only how many people have lost their jobs but also what impact the shutdown will have on the community. To answer that larger question, they need to know whether the company was one of the largest employers in the area, whether other local companies provide the same product or service, what the local unemployment rate is, and so on.

The business beat requires a deeper knowledge of mathematics and statistics than most other topic areas. But business reporters should use numbers sparingly in their stories, because too many figures make a story dry and dull. The most compelling business stories show the significance of developments by putting them in human terms, describing how individuals have been or will be affected.
Health, Science, and the Environment

S tories about health and the environment have a direct impact on people's lives. Reporters who cover AIDS know that ignorance can be almost as dangerous as the disease itself; their stories can educate people so they can protect themselves. Journalists on the health, science, and environment beat may report about everything from avian flu to the mapping of the human genome and the effects of damming rivers. For each of these topics, the underlying issues are complicated and the journalist's job is to explain them clearly.

When dealing with these kinds of stories, journalists need to be familiar with the language of scientists and medical researchers, which can be confusing to laymen. Don't be intimidated by it, says reporter Dennis Bueckert of the Canadian Press news agency, and don't use it in your stories, either. Like business reporters, science writers develop their own list of definitions and explanations for complicated terms so they can write stories that make sense to the general public.

Reporters who cover scientific subjects need to understand the scientific method, basic mathematics, and statistics, so they can double-check the results of research studies. At the same time, they should resist the urge to turn every development into a breakthrough, or to press for "yes" or "no" answers instead of accepting probabilities. Their stories may not seem as dramatic but they will certainly be more accurate.

Journalists who are trained to report all sides of a story often fall into a trap when covering science. Giving even-handed coverage to differing scientific opinions can actually mislead the audience. For example, 
Court reporters must understand the judicial process from beginning to end. They should know what happens when a suspect is arrested, charged, arraigned, tried, and sentenced or released. Experienced reporters say the best way to learn the process is to spend time at the courthouse. Begin with the court clerks, who keep track of the docket - the list of cases - and the calendar. Find out how to get copies of the court record, filings, and testimony. Read the case files - including motions and pleadings before the trial - and keep track of what's reported about the case if you can't be in court every day, which frequently happens.

Defense attorneys are some of the best sources of information on the justice beat. They often are more willing than prosecutors to talk with reporters about cases on which they are working. Do your best to understand legal jargon, but avoid using it in your stories. "Lawyers are counseled to use big words to confuse journalists," says S.L. Alexander, author of Covering the Courts: A Handbook for Journalists. "If you don't know what something means, ask the person you're interviewing to explain it," she advises.

\section{Sports}

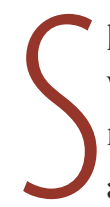
ports reporters do some of the best writing in journalism. Their stories naturally involve drama, emotions, and outsized personalities, says former TV sports reporter Bill Schwanbeck, who now teaches at Quinnipiac University in Connecticut. Good sportswriters do much more than report the score of a game or the results of an athletic competition. They provide the basics, of course, but they also provide perspective and context that the audience can't get from being at the game or watching it on television. Sportswriters explain the why and how of what happened, not just the who and the what. They also report on the business of sports, and write feature stories about athletes, team owners, and fans.

But sports reporters still have to start with the fundamentals. They need to be knowledgeable about all sports, understand the rules of the game or sport they are covering, and how the score is determined. They work on very tight deadlines, especially when covering night games. They have to keep score and make notes at the same time, not an easy task during a fast-moving game. Most importantly, they need to find a theme for each story and build the details around it.

In many cases, the best story is not on the field. Sportswriters probe for what's happening behind the scenes, the atmosphere in the locker room, or the tension between two players that might be affecting the entire team. They treat players and managers with respect, but they do not engage in hero-worship. They often enjoy the sports they cover, but they are not fans or boosters of any one team. Like all journalists, they should be fair and independent observers of the stories they cover. 
Just as business and science reporters avoid economic and business jargon, sportswriters should avoid terms that only the most ardent fan or coach would know. "Keep it simple," says former sports reporter Mike Reilley, now publisher of the online site The Journalist's ToolBox. "Don't get cute." He also warns young journalists to expect some interviews with athletes and coaches to be confrontational, especially after a loss. Many professional athletes thrive on intimidation, Reilley says, so be prepared to stand your ground.

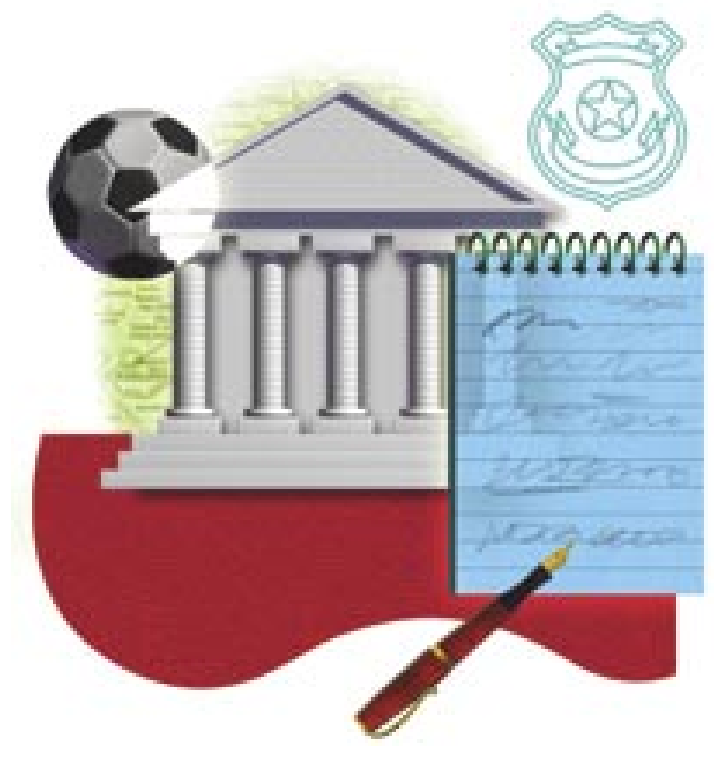

Questions Journalists Should Ask About Polls

- Who did the poll? Is this a legitimate survey organization? Who else do they poll for?

- Who paid for the poll? What is their political agenda?

- How many people were interviewed?

- How were they selected?

- What kinds of people were interviewed?

- Are the results based on answers of all or some of those polled?

- When was the poll conducted?

- How was the poll conducted?

-What were the questions?

- What was the margin of error? What were the raw numbers?

- Are the results different from other polls and, if so, why?

- Is this poll worth reporting?

\section{Excerpted with permission from} 20 Questions a Journalist Should Ask About Poll Results, Third Edition, by Sheldon R. Gawiser, Ph.D., and G. Evans Witt. http://www.ncpp.org 
ETHICS AND LAW

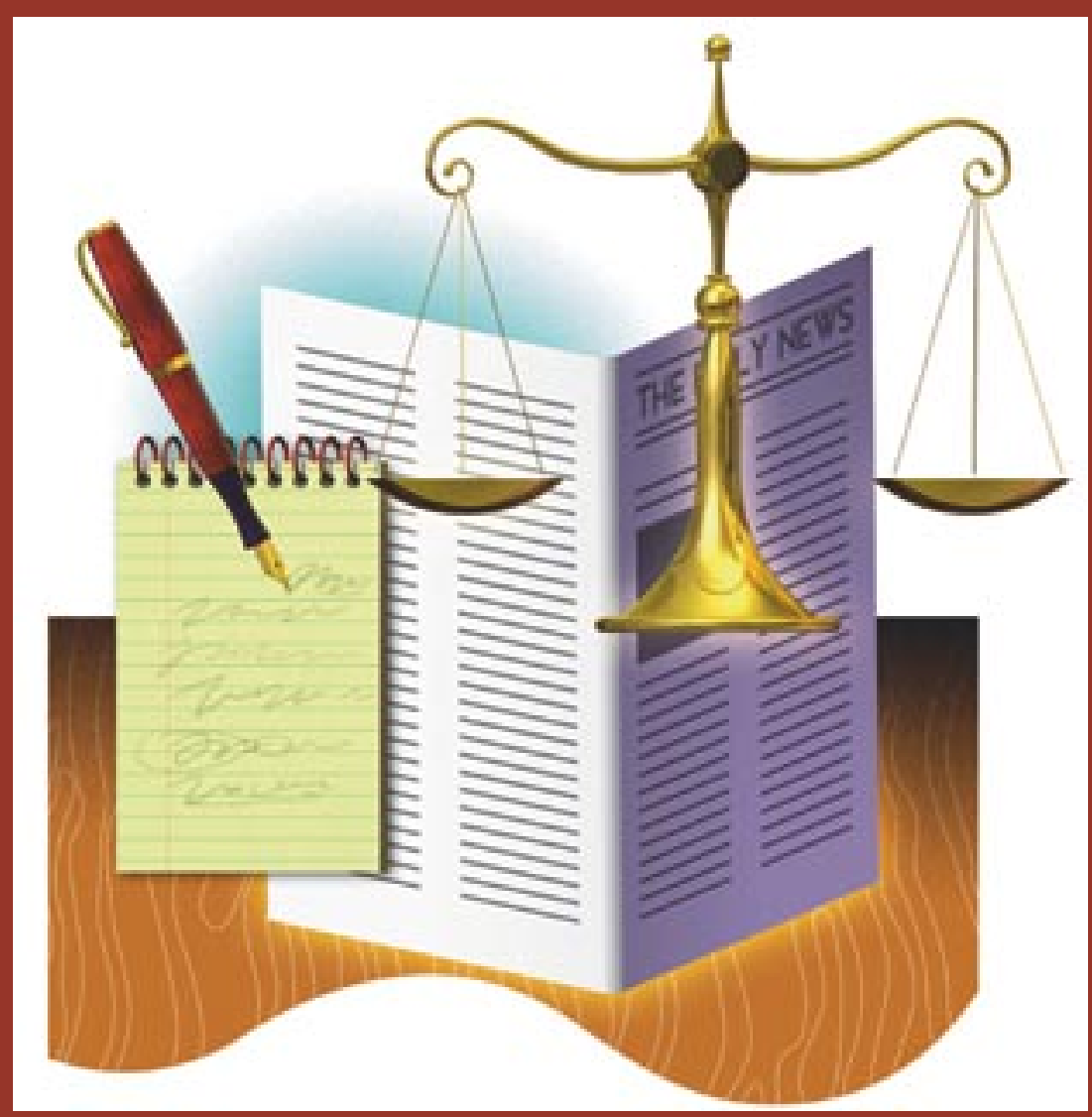




\section{A free press has tremendous power, if power is defined as the}

\section{capacity to influence others. The news media in a democracy}

generally have the right to report information without prior government approval. Many countries provide legal protections to journalists so they can exercise that right. But with rights

come responsibilities. For journalists, the most basic responsibility in a free society is to report the news accurately and fairly: to practice ethical journalism.

Ethics is a system of principles that guides action. While the law establishes what you can and cannot do in a given situation, ethics tells you what you should do. It is based on values - personal, professional, social, and moral and springs from reasoning. Ethical decisionmaking simply means applying these values in your daily work.

The Declaration of Chapultepec, approved by countries in the Americas in 1994 as a counter to pressures on freedom of expression throughout the hemisphere, makes clear that ethical journalism is essential to the long-term success of the news media:

The credibility of the press is linked to its commitment to truth, to the pursuit of accuracy, fairness, and objectivity and to the clear distinction between news and advertising. The attainment of these goals and the respect for ethical and professional values may not be imposed. These are the exclusive responsibility of journalists and the media. In a free society, it is public opinion that rewards or punishes.

Ethical lapses do occur in journalism. Reporters have invented information. Editors have accepted payments from sources. News organizations have published advertisements in the guise of news. When this happens, the public has a right to question everything that appears in the news media. All journalists, and all news organizations, suffer when journalists behave unethically because that behavior calls the profession's credibility into question. When credibility suffers, so does a news organization's ability to survive economically.

\section{Ethical Principles}

T here is one sacred rule of journalism," said the late reporter and prize-winning novelist John Hersey, who covered the aftermath of the atomic bomb attack on Hiroshima. "The writer must not invent. The legend on the license must read: NONE OF THIS WAS MADE UP." Ethical journalists do not put words in people's mouths or pretend to have been somewhere they have not. And they do not pass off the work of others as their own. Fabrication and plagiarism are violations of basic journalistic standards the world over. But not all transgressions are so clear.

Journalists face ethical dilemmas every day, under pressure from owners, competitors, advertisers, and the public. They need a process to resolve these dilemmas, so that the journalism they produce is ethical. They need a way of thinking about ethical issues that will help them make good decisions, even on deadline. 


\section{For journalists,}

\section{the most basic}

\section{responsibility in}

a free society is

to report the news

accurately and

$$
\text { fairly. }
$$

This way of thinking is grounded in the principles journalists rely on. These are the basic principles of the U.S. Society of Professional Journalists, a voluntary journalism organization:

- Seek truth and report it.

Journalists should be honest, fair, and courageous in gathering, reporting, and interpreting information.

- Minimize harm.

Ethical journalists treat sources, subjects, and colleagues as human beings deserving of respect.

- Act independently.

Journalists should be free of obligation to any interest other than the public's right to know.

- Be accountable.

Journalists are accountable to their readers, listeners, viewers, and each other.

On the surface, it may seem easy enough to abide by these principles. Of course, journalists should seek the truth and treat their sources with respect. But oftentimes, the principles themselves are in conflict. Journalists who seek the truth may discover information that will be hurtful to the family of a person involved in wrongdoing. A reporter's membership in a non-governmental organization may allow her to learn more about a story the group is involved with, but her association with the group may also compromise her independence and be difficult to justify to the audience. In many cases, making an ethical decision means choosing not between right and wrong but between right and right.

How, then, can journalists possibly make good ethical decisions? Some situations are best dealt with by avoiding them in the first place. For example, reporters may choose not to belong to any outside groups, or they may disqualify themselves from covering stories involving any groups they do belong to. In other cases, a journalist must seek the best possible balance between conflicting principles, always keeping in mind the primary importance of seeking the truth and serving the public.

\section{Ethical Decision-Making}

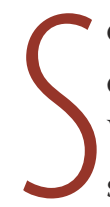

ome newsrooms deal with ethical quandaries from the top down.

Whenever an issue or dilemma arises, a senior manager decides what to do. This approach has the advantage of being quick, but it can be arbitrary. It does nothing to help journalists make good decisions when they are out in the field or when the manager is unavailable. For that reason, many newsrooms have adopted an ethical decision-making process that is more inclusive and that helps all journalists make good decisions under a variety of circumstances.

The first step in the process is to define the dilemma. Most people recognize when they are facing an ethical quandary. An internal alarm goes off. Something does not feel quite right about a situation. When that happens, it's important to spell out what's bothering you. What are the values that may be compromised? What journalistic issues are at stake? Often there is tension between a journalistic goal and an ethical stand. The reporter who has an exclusive story may want to rush it into print before any one else gets it, but he also needs to consider the possible consequences. What if the story turns out to be wrong? Journalists should not sacrifice their ethical values to achieve other objectives, such as beating the competition. 
The next step after defining the problem is to collect more information to help you make a good decision. Consult newsroom policies and guidelines, if any exist, and talk to others about the dilemma. Begin with colleagues and supervisors in the newsroom, but don't stop there. It's often useful to include other voices, people who are not directly involved in the story but who are knowledgeable about the circumstances.

It's important to note that journalists, unlike doctors, are not expected to promise to do no harm. Many truthful and important stories will hurt people's feelings or reputations. It's inevitable. But journalists do try to minimize the harm by not putting people at unnecessary risk. Bob Steele, who teaches journalism ethics at The Poynter Institute, likes to ask: "What if the roles were reversed? How would I feel?"

Let's say a reporter has discovered a factory where boys under the age of 12 work 10 hours a day, six days a week, and are paid less than half the country's minimum wage. The country's constitution prohibits employers from hiring anyone under 14 and it is illegal for anyone to work more than 45 hours a week. Finding the factory means the reporter has proof of child exploitation, but what more does he need to know before publishing or broadcasting the story?

Telling the truth about the factory would certainly have consequences, and some of them could be hurtful. When faced with this kind of story, it can be helpful to create a list of people and institutions that might be affected by the

\section{Ethical journalism is essential to the long-term success of the news media.}

story and to consider the impact the story might have. The story about the factory would affect the boys directly, of course, but it would also affect their families and the factory owner. Knowing the possible consequences, journalists can begin to look at alternatives for presenting the information so the story remains truthful but does not cause as much harm. In the case of the factory, the journalist might decide to use photos of the children but not to name them, in an effort to limit the potential harm the story could cause.

That's just one example of a journalistic decision that can have ethical consequences. Others include the type and placement of the coverage, as well as its tone. The impact of a front-page story with a banner headline and a large photograph is considerably greater than a smaller story that runs on an inside page. A television story that is promoted multiple times before it airs would have more impact, and therefore greater ethical consequences, than a story told once in the middle of a newscast.

Going through a process to make good ethical decisions puts journalists and news organizations in a position to justify their actions clearly. By explaining what was done and why, journalists are able to bolster their credibility and justify the public's trust in them.

Newsrooms that value ethical decisionmaking make sure these kinds of issues are discussed, and not just when a dilemma occurs. Some newsrooms hold regular meetings to discuss what they would do in hypothetical situations. Journalists who practice listening with an open mind and who keep their emotions in check and avoid becoming inflexible about their positions are able to put these skills to work when facing a real ethical concern. 


\section{Ethics Codes}

ournalism associations and federations around the world have established codes of ethics to guide the work of member journalists. Ethics codes can cover everything from plagiarism to privacy and from corrections to confidentiality. Some are brief and vaguely worded, while others are lengthy and quite explicit. Claude-Jean Bertrand, who is a professor at the University of Paris's French Press Institute and has examined ethics codes from many countries, says that most include these three basic elements:

- Fundamental values, including respect for life and human solidarity;

- Fundamental prohibitions, including not to lie, cause needless harm, or appropriate someone else's property;

- Journalistic principles, including accuracy, fairness, and independence.

These codes are sometimes voluntary in nature, with no clear consequences for violators. But the expectation is that peers and employers will hold journalists who behave unethically accountable. In some countries, press councils hear complaints against journalists and can recommend action to correct mistakes. Journalism review magazines also serve a corrective function by exposing the behavior of unethical journalists. Some news organizations have a staff person, commonly called an "ombudsman," who watches out for errors and ethical lapses and serves as the public's representative inside the newsroom.

In countries where journalists are required to belong to a union or association, ethics codes often include an enforcement provision. For example, the Australian Journalists Association has judiciary committees that investigate charges of unethical behavior brought against journalists. A journalist found in violation can be rebuked, fined, or expelled from the group.

\section{Codes of Conduct}

$\mathrm{n}$ addition to national and regional codes of ethics, many news organizations have their own codes of conduct or standards of practice that they expect their journalists to follow. These codes may spell out specific actions or activities that are either encouraged or prohibited, or that require the approval of a manager.

Many news organizations limit what journalists can do both on and off the job. The main reason for these limitations is to protect the credibility of news organizations. Reporters and photographers may be told explicitly that they cannot manipulate or "stage" the news by asking people to do something for a story that they would not do ordinarily. Reporters may not be allowed to conceal their identities to get a story, unless there is a clear and compelling public interest in the information and it cannot be obtained any other way. A television station may explicitly forbid the use of hidden cameras or surreptitious recording in gathering the news, unless a manager approves it for publicinterest reasons.

With the advent of digital photography, new standards have been added to prohibit altering photographs or video in a way that could mislead the audience. Several highprofile incidents contributed to these new policies, including a photograph on the cover of National Geographic magazine in the 1980s that digitally moved the famous Pyramids of Giza in Egypt closer together.

Many of the regulations in newsroom codes of conduct address issues of journalistic independence. To avoid even the appearance of a conflict of interest, reporters may be forbidden to own stock or have a personal interest in companies they cover. Journalists may not be allowed to take a public position on a political issue or openly support a candidate for office. The news organization may prohibit journalists from having a business relationship with any news source, or from doing any outside work for pay unless approved by a manager. 
The ethics policy of the Detroit Free

Press, an American newspaper in the state of Michigan, clearly spells out what the newspaper will and will not do. It prohibits paying sources for news and says that sources will not be allowed to review material before publication. The Canadian Broadcasting Company (CBC) has a lengthy standards manual that requires employees to refuse any gifts that may appear to influence a CBC decision; only modest gifts of goodwill or hospitality offered during the conduct of normal business may be accepted. CBC employees may not accept offers of free travel or accommodations in order to cover a story.

It may not be possible to avoid every potential conflict, but journalists need to be aware that their conduct can reflect badly on the news organization. When they sense that a conflict might arise, they should be expected to notify their supervisors. A reporter with a personal connection to a story may ask that a different reporter take on the assignment. Many news organizations have made it their practice to have reporters disclose relationships in their stories that could even suggest a conflict of interest, even if none exists.

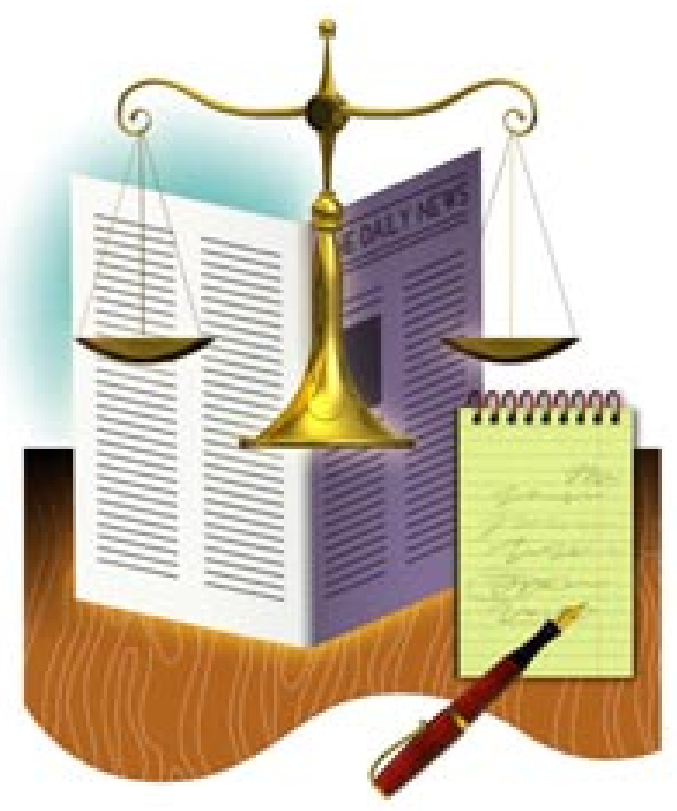

Codes of conduct are typically internal documents, but more and more news organizations are posting them on their Web sites so the public knows what to expect and can hold the newspaper or station accountable if its standards are violated.

\section{Community Standards}

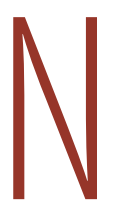
ews organizations often face conflicts between newsworthiness and community standards, and resolving them requires the skilful practice of ethical decision-making. Suppose an elected official has used a racial slur in discussing a member of the opposition party. Some newspapers might print the exact words the official used. Others could use a few letters followed by dashes to indicate what he said without spelling it out. And some newspapers would likely report only that the official had used offensive language. Newspaper editors choose different solutions depending on what they feel the readers would be willing to tolerate. But sometimes they go ahead with a decision they are certain would offend some readers. Editors face similar difficult choices when it comes to shocking photographs or video the audience may find distasteful, but that may be the most powerful way to tell an important story.

To minimize the harm such a choice might cause, many news managers now choose to explain why they made the decision they did, either in the text of the story or in a separate "editor's note" alongside it. For example, a photograph of a mother holding the emaciated body of her son who died of starvation would certainly be disturbing. Instead of waiting for angry phone calls and responding to each individual complaint, the editor's note might say that this picture of suffering tells the story of famine much more clearly than words alone. By explaining their decisions to the public, journalists can live up to the guiding principle of accountability. 


\section{Legal Issues}

\section{T}

he cornerstone of international

standards on the news media is Article 19

of the United Nations Charter,

which states:

Everyone has the right to freedom of opinion and expression; this right includes freedom to hold opinions without interference and to seek, receive, and impart information and ideas through any media and regardless of frontiers.

Countries that are members of the United Nations are committed to upholding the charter, including Article 19, but that hasn't stopped some countries from suppressing their own news media and blocking access to international news. In some cases, journalists have been killed, imprisoned, or exiled for trying to do their jobs.

Danilo Arbilla of the Inter American Press Association and Uruguay's Búsqueda says the best press law is no law at all. In the ideal world, he says, legislation governing press freedom would take up no more than a couple of pages, "containing clear and frankly worded clauses prohibiting any attempt to regulate ... freedom of expression." Needless to say, the world is not an ideal place. Press laws vary around the world to such an extent that it is not possible to summarize them all. Some democratic countries have laws to ensure journalists' access to public information, while others limit what information can be published or aired. In some countries, it is illegal to name the victim of a sexual crime, or to identify juveniles accused of criminal activity. Even within countries, there may be differing local laws covering issues such as whether a journalist can be forced to name a confidential source or provide reporting notes to a court of law, and under what circumstances. Suffice it to say that journalists need to be aware of the laws in the countries in which they work, as well as ongoing efforts to have restrictive laws lifted.
One of the most common kinds of legal issues journalists face is libel or defamation. In the United States, defamation is a statement of fact that is substantially false about someone who can be identified and that tends to injure that person's reputation. Defamation is called "libel" when the statement is published and "slander" when it is broadcast, but the basic parameters are the same. Generally speaking, if a statement is true, it cannot be defamatory. Journalists therefore must confirm independently what their sources say, if those comments could defame another person.

As new technology changes the way journalists do their work, media laws are being reexamined. At the forefront are questions such as: Should online reporters be granted the same rights and protections as journalists working for established news organizations? Should those same privileges extend to Internet bloggers? These questions are likely to remain unresolved for some time.

Reporters obviously are subject to other laws that apply to individuals in a given country, such as laws governing privacy. A journalist who wants access to information cannot enter private property, take documents without permission, or wiretap a telephone and expect to face no legal consequences. A news organization might decide that some stories are so important they are worth the risk of legal sanctions, but that is a different matter to be decided jointly and carefully by editors, reporters, and management. 


\section{JOURNALISM RESOURCES}

\section{Membership Groups}

\section{American Society of Newspaper Editors}

http://www.asne.org/

Represents daily newspaper editors in the

Americas.

\section{Association for Women Journalists}

http://www.awjdfw.org/index.html

Promotes fair treatment of women in the media and the newsroom through a scholarship program, career grants, networking, advocacy, career seminars, and the annual Vivian Castleberry Awards Competition.

\section{International Federation of Journalists}

http://www.ifj.org/

Represents around 500,000 members in more than 100 countries.

\section{Investigative Reporters and Editors, Inc.} http://www.ire.org/

Represents investigative journalists.

National Press Photographers Association http://www.nppa.org/

Serves print and television photojournalists.

\section{Online News Association}

http://www.journalists.org/

Serves online-media journalists.

\section{Organization of News Ombudsmen}

http://www.newsombudsmen.org/

International association of ombudsmen, or internal newsroom critics.

\section{Radio-Television News Directors} Association

http://www.rtnda.org

Membership group for electronic journalists worldwide.

\section{Society of Professional Journalists}

http://www.spj.org/

The Society of Professional Journalists works to improve and protect journalism. SPJ also promotes the free practice of journalism and high ethical standards of behavior. Encourages the free flow of information vital to a wellinformed public, works to educate the next generation of journalists, and protects First Amendment guarantees of freedom of speech and press.

\section{Society for News Design}

http://www.snd.org/

Represents designers, graphic artists, illustrators, and other visual journalists.

\section{Reporting and Editing}

\section{Cyberjournalist.net}

http://www.cyberjournalist.net/tips_and_ tools/

CyberJournalist.net is a resource site that focuses on how the Internet, convergence (see note), and new technologies are changing the media. The site offers tips, news, and commentary about online journalism, citizen's media, digital storytelling, converged news operations, and using the Internet as a reporting tool. 
Note: Convergence in the media refers

to cross-platform reporting. For example:

newspaper reporters file stories for the

newspaper, the paper's Web site, and even a

$T V$ or radio station owned by the newspaper.

\section{Journalism.net}

http://www.journalismnet.com

A full service site with dozens of useful links, developed by a Canadian reporter.

\section{NewsLab}

http://www.newslab.org

Resources, story background, and training for television and radio journalists.

\section{Project for Excellence in Journalism}

http://www.journalism.org

U.S. non-profit organization has resources and research.

\section{Reporter.org}

http://www.reporter.org

Resources for journalists, including beat-related links.

\section{Specialized Journalism}

Most of these groups are membership organizations that offer training at regularly scheduled conferences and resources on their Web sites.

\section{BUSINESS: National Center for Business}

\section{Reporting}

http://www.businessjournalism.org/

CONFLICT: Center for War, Peace, and the News Media

http://www.bu.edu/globalbeat/

\section{ENVIRONMENT: International}

\section{Federation of Environmental Journalists}

http://www.ifej.org/
INVESTIGATIVE: International Consortium of Investigative Journalists

http://www.publicintegrity.org/icij/

\section{SCIENCE: International Science Writers} Association

http://internationalsciencewriters.org/

SPORTS: Associated Press Sports Editors http://apse.dallasnews.com/

\section{Journalism Training}

\section{American Press Institute}

http://www.americanpressinstitute.org/ Training center for print journalists based in the United States. Site offers resources, including useful links at The Journalist's Toolbox.

\section{CIESPAL}

http://www.ciespal.net/

International journalism center for Latin America, based in Ecuador. (Site is in Spanish.)

\section{European Journalism Centre}

http://www.ejc.nl/

Training institute based in The Netherlands, has background information on European media and resources.

\section{IFRA Newsplex}

http://www.newsplex.org/home.shtml Training centers in the United States and Germany.

\section{Independent Journalism Foundation} http://www.ijf-cij.org/

Supports free press in Eastern Europe with training at four regional centers.

\section{International Center for Journalists}

http://www.icfj.org

Training center based in the United States also has links to worldwide training and fellowship opportunities on its International Journalists' Network: http://www.ijnet.org/ 


\section{Internews}

http://www.internews.org/

U.S. non-profit group offers journalism training around the world.

\section{Institute for the Advancement of} Journalism

http://www.iaj.org.za/

South African media training institute.

\section{Institute for War and Peace Reporting}

http://www.iwpr.net

Special reports by region from this Londonbased non-profit, in multiple languages.

\section{John S. Knight Fellowships}

http://knight.stanford.edu/program/index.html Offers one-year professional journalism fellowships at Stanford University for outstanding mid-career journalists.

\section{Journalismtraining.org (Society of} Professional Journalists)

http://www.journalismtraining.org/action/ home

Provides a centralized location for journalists seeking information about professional development. The centerpiece of the site is a searchable database of local, regional, and national journalism training programs.

\section{No Train-No Gain}

http://www.notrain-nogain.org/

Newspaper training editors share ideas and exercises on this site.

\section{The Poynter Institute}

http://www.poynter.org/

A school for journalists, based in the United States. Web site provides resources, story background information, and plenty of links.

\section{Freedom of Expression}

\section{Article 19}

http://www.article19.org/

International non-profit group supports freedom of expression and the free flow of information as fundamental human rights.

\section{Canadian Journalists for Free Expression} http://www.cjfe.org/

Nongovernmental group defends the rights of journalists throughout the world.

\section{Freedom Forum}

http://www.freedomforum.org/

News outlet dealing primarily with U.S. First Amendment and Freedom of Information issues.

\section{Inter American Press Association}

http://www.sipiapa.org/

Supports free press in the Western Hemisphere.

\section{Journalists for Human Rights}

http://www.jhr.ca/

Canadian-based nonprofit, focused on reporting in Africa.

\section{The Reporters Committee for Freedom of} the Press

http://www.rcfp.org/

A nonprofit organization dedicated to providing free legal assistance to journalists.

\section{Reporters Without Borders}

http://www.rsf.org/

International press freedom organization, based in Paris. Resources in English, French, and Spanish.

\section{World Press Freedom Committee}

http://www.wpfc.org/

International umbrella group defends and promotes press freedom. 


\section{Books}

Clark, Roy Peter and Cole C. Campbell (eds.) The Values and Craft of American Journalism: Essays From The Poynter Institute. Gainesville, FL: University Press of Florida, 2005.

The First Amendment Handbook. Arlington, VA: The Reporters Committee for Freedom of the Press, 2003.

http://www.rcfp.org/handbook/index.html

Hachten, William A. Troubles of Journalism: A Critical Look at What's Right and Wrong With the Press. Mahwah, NJ: Lawrence Erlbaum Associates, 3rd edition, 2004.

Hamilton, James T. All the News That's Fit to Sell: How the Market Transforms Information Into News. Princeton, NJ: Princeton University Press, 2003.

Overholser, Geneva, and Kathleen Hall Jamieson. The Press. New York, NY: Oxford University Press, 2005.

Sloan, W. David and Lisa Mullikin Parcell (eds.) American Journalism: History, Principles, Practices. Jefferson, NC: McFarland \& Company, 2002.

Sullivan, Marguerite H. A Responsible Press Office: An Insider's Guide. Washington, DC: U.S. Department of State, International Information Programs, 2001. http://usinfo.state.gov/products/pubs/ pressoffice/

\section{Ethics Codes}

\section{American Society of Newspaper Editors}

ASNE Statement of Principles. Reston, VA:

American Society of Newspaper Editors, 2002. http://www.asne.org/kiosk/archive/ principl.htm

\section{Radio-Television News Directors}

\section{Association}

Code of Ethics and Professional Conduct.

Washington, DC: Radio-Television News

Directors Association, 2000.

http://www.rtnda.org/ethics/coe.shtml

\section{Society of Professional Journalists}

SPJ Code of Ethics. Indianapolis, IN: Society of Professional Journalists, 1996.

http://spj.org/ethics.asp

\section{International Center for Journalists}

Code of Ethics (by country and region). Washington, DC.

English version: http://www.ijnet.org/ Director.aspx?P=Ethics
The U.S. Department of State assumes no responsibility for the content and availability of the resources from other agencies and organizations listed above. All Internet links were active as of Fall 2006. 
Executive Editor : George Clack

Writer : Deborah Potter

Editor : Mildred Solá Neely

Art Director/Design : Min-Chih Yao

Illustrations : Bryan Leister

This publication is a companion volume to

A Responsible Press Office: An Insider's

Guide by Marguerite H. Sullivan

(http://usinfo.state.gov/products/pubs/

pressoffice/).

The opinions expressed in this publication do not necessarily reflect the views or policies of the U.S. government.

Bureau of International Information Programs

U.S. Department of State

http://usinfo.state.gov/

2006 
Bureau of International Information Programs U.S. DEPARTMENT OF STATE http://usinfo.state.gov/ 